\title{
Synthesis process and hydrodynamic behavior of a new filtration material for passive wastewater dephosphatation
}

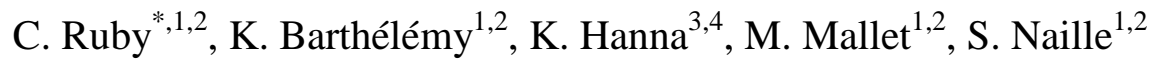 \\ ${ }^{1}$ Université de Lorraine, Laboratoire de Chimie Physique et Microbiologie pour l'Environnement \\ (LCPME), UMR 7564, 405 rue de Vandœuvre, F-54600 Villers-lès-Nancy, France. \\ ${ }^{2}$ CNRS, Laboratoire de Chimie Physique et Microbiologie pour l'Environnement (LCPME), UMR \\ 7564, 405 rue de Vandouvre, F-54600 Villers-lès-Nancy, France. \\ ${ }^{3}$ Ecole Nationale Supérieure de Chimie de Rennes, UMR CNRS 6226, 11 Allée de Beaulieu, CS \\ 50837, F-35708 Rennes cedex 7, France \\ ${ }^{4}$ Université Européenne de Bretagne, 4 Boulevard Laennec, F-35700 Rennes, France.
}

\footnotetext{
* Corresponding author. Tel.: +33 (0)3 836852 53; fax: +33 (0)3 83275444

E-mail address: christian.ruby@univ-lorraine.fr
}

Submitted to Materials \& Design 


\section{Abstract}

2 The preparation optimization of a filter material intended to be used as a phosphate sorbent in

3 flow-through conditions is investigated. The mixing of ferrihydrite ( $\mathrm{Fh})$ and pozzolana $(\mathrm{Pz})$

4 using a "dry contact method" is found to be the most efficient and leads to the formation of a

5 micrometric thick Fh coating deposited into the honeycombed structure of Pz. The maximal

6 Fh content of $\sim 8.5$ wt. \% is significantly higher than the quantity deposited on other classical

7 substrates such as sand. The phosphate sorption kinetics and isotherms, under dynamic

8 conditions in batch experiments, are best described by pseudo-second-order and Freundlich

9 models respectively. Moreover, under static conditions, sorption kinetics reveals intra-

10 aggregate diffusion process. Phosphate ions retention in packed columns, and especially the

11 breakthrough point, can be adequately predicted when coupling the classical convection

12 dispersion equation and the surface complexation model. Breakthrough curves of phosphate

13 ions are strongly dependent on flow rate; which is important for future industrial applications.

14 Finally, and unexpectedly, a high value of phosphate adsorption capacity $\left(80 \mathrm{mg} \mathrm{PO}_{4} \mathrm{~g}^{-1}\right)$ is

15 observed when phosphate-containing wastewater is used as feed solution. This is mostly

16 explained by soluble calcium ions, which favors the phosphate fixation onto the filter material

17 surface.

19 Keywords: ferrihydrite, pozzolana, phosphate, flow through, adsorption 


\section{Introduction}

With the continuous growth of the world population and the development of industry and agriculture, water protection has become one of the major environmental challenges of the $21^{\text {st }}$ century. Among the various pollutants that threaten water quality, pollution by phosphate and nitrate anions remains a recurrent problem at the origin of eutrophication leading to severe perturbations of fresh and sea water biodiversity. Eutrophication compromises different branches of business such as tourism (green tides, swimming bans), fishing and production of drinking water (closing of water catchments, complications of water treatment). Numerous preventive actions tend to limit the use of products containing nitrogen and phosphorous, in particular fertilizer. Curative treatments of waste water are also necessary to limit the eutrophication phenomena and considerable efforts are achieved in the urban area of the industrial countries. For example, the treatment of organic matter, phosphate and nitrate present in municipal wastewater is nowadays relatively well controlled, especially by using the activated sludge process. A complementary chemical treatment by precipitating phosphate with aluminum or ferric salts is sometime necessary. However, such treatments are generally not suitable for rural areas where the building costs and maintenance of wastewater treatment plants (WWTPs) would be too high and other collective sanitation systems are used such as lagoon based WWTPs and reed or sand bed filters. Such passive systems are particularly interesting because they consume very little energy and need little maintenance. However, despite the fact that the organic matter release is generally satisfactory, the rate of denitrification and dephosphatation remains too low [1]. Therefore, recent research efforts have been devoted to develop new materials and new processes for combined passive treatments of phosphate and nitrate [1,2]. Interesting results were also obtained at the industrial scale by using minerals such as apatite [3], Filtratite- $\mathrm{P}^{\circledR}$ [4] or slag from the steel industry [5] for dephosphatation. Although these materials are advantageous in term of supply 
cost, ferric oxides have a stronger affinity for phosphate anions leading to phosphate sorption capacity as high as about $80 \mathrm{mg} \mathrm{PO}_{4}$ per gram of material at circumneutral $\mathrm{pH}$ [6]. Iron oxyhydroxides with nanometric crystal size such as ferrihydrite, or mesoporous spheres [7], present particularly high phosphate adsorption capacity. However, such nanomaterials cannot be used directly as a filter material due to problems of water clogging and release of rustcolored water. One can distinguish three ways for preparing filter materials containing iron oxides: (i) the granulation of ferric oxide nanoparticles into millimetric size particles [8], (ii) the elaboration of composite materials including ferric oxides embedded into various matrices such as polymer [9], silica [10] or zeolithe [11], and (iii) the deposition of iron oxide coatings onto support such as sand [12] or activated carbon [13]. On the contrary to classical ferric or aluminium salts, such filter materials can be used in flow-through conditions if the iron oxides particles are physically and chemically stabilized.

Recent work performed in our laboratory led to the discovery of a new synthesis process allowing the preparation of thick iron oxide coatings onto a support of a pozzolana volcanic rock [14]. This paper describes in a first step the optimization of the synthesis process and the solid and surface characterizations of this new material. In a second step, the sorption capacity of the material is evaluated in both batch and column experiments. The batch tests allow determining the kinetic rate and sorption capacity in various experimental conditions (phosphate concentration and $\mathrm{pH}$ ). The breakthrough curves (BTC) of phosphate are determined under different water velocities and column residence times. Predictions of BTC are developed from surface complexation modeling parameters derived from batch sorption data. The effect of chemical non-equilibrium and physical diffusion limitations on the breakthrough behavior is also discussed. Finally, the phosphate sorption capacity of the material is evaluated under flow-through conditions, but by using phosphate-containing wastewater (arising out of WWTPs) as a feed solution. 


\section{Experimental}

\subsection{Materials}

\subsubsection{Chemicals}

All reagents, i.e. iron(III) chloride hexahydrate $\left(\mathrm{FeCl}_{3} \cdot 6 \mathrm{H}_{2} \mathrm{O}\right.$, Sigma-Aldrich, $\left.\geq 99 \%\right)$, sodium hydroxide $(\mathrm{NaOH}$, Carlo Erba, > 99\%), sodium phosphate monobasic dihydrate $\left(\mathrm{NaH}_{2} \mathrm{PO}_{4} \cdot 2 \mathrm{H}_{2} \mathrm{O}\right.$, Sigma-Aldrich, $\left.\geq 99 \%\right)$, sodium chloride (NaCl, Sigma-Aldrich, $\left.\geq 99.8 \%\right)$, potassium bromide $(\mathrm{KBr}$, Sigma-Aldrich, $\geq 99 \%)$ and calcium nitrate tetrahydrate $\left(\mathrm{Ca}\left(\mathrm{NO}_{3}\right)_{2} \bullet 4 \mathrm{H}_{2} \mathrm{O}\right.$, Sigma-Aldrich, 99-103\%), were of analytical grade. The supporting material, pozzolana (Pz), was supplied by "Pouzzolanes des Domes" (St-Ours-les-Roches, France) and was characterized by a grain size ranging from $\sim 0.1$ to $\sim 0.3 \mathrm{~cm}$. Such a grain size allows an adequate permeability during the flow through experiments. Demineralized water was used through the experiments unless otherwise specified, and all experiments were performed in duplicate which means that mean values are reported. One of the column experiments was performed by using water supplied by a SAUR ${ }^{\circledR}$ sewage treatment plant (Dombasle-sur-Meurthe, France) with the physico-chemical characteristics of Table 1.

\subsubsection{Filter material preparation and characterization}

Ferrihydrite (Fh) was synthesized following the method described by Mallet et al. [15] using a slightly modified procedure from that reported in Cornell and Schwertmann [16]. Fh was prepared by rapid hydrolysis of $0.8 \mathrm{M} \mathrm{FeCl}_{3} \bullet 6 \mathrm{H}_{2} \mathrm{O}(500 \mathrm{~mL})$ with $3 \mathrm{M} \mathrm{NaOH}$ at $\mathrm{pH} 7.5$. This $\mathrm{pH}$ value was maintained for $\sim 3 \mathrm{~h}$ under vigorous stirring and then the precipitate was centrifuge-washed until the surface chloride atomic concentrations determined by X-ray Photoelectron Spectroscopy (XPS) were reduced below $~ 3$ at.\%. The pastes were then dried at room temperature and ground in an agate mortar. The pristine Fh was characterized by powder X-ray Diffraction (XRD) on a D8 Advance diffractometer (Brucker AXS GmbH, 
Karlsruhe, Germany) using a monochromatic $\operatorname{Co~} \operatorname{K} \alpha_{1}$ radiation $(\lambda=1.78897 \AA)$. The resulting diffraction pattern is characteristic of nano-crystalline two-line Fh [17,18], showing two low-intensity broad peaks with interplanar spacing values of $c a .2 .61$ and $1.50 \AA$ (Fig. S1). The specific surface area of ferrihydrite, determined by $\mathrm{N}_{2}$ physical adsorption at $77 \mathrm{~K}$ on a Belsorp-max analyzer (BEL Japan Inc., Osaka, Japon) using the Brunauer-Emmett-Teller (BET) method, is $310 \mathrm{~m}^{2} \mathrm{~g}^{-1}$, in good agreement with previously reported values $[19,20]$.

The filter material ( $\mathrm{Fh}-\mathrm{Pz})$ preparation was adapted from that previously reported for Fh-coated sand $[21,22]$. Three synthesized routes were investigated in order to optimize the amount of Fh coated onto Pz. The first method ("reactive" method) consisted in Fh precipitation in the presence of Pz. $20 \mathrm{~g}$ of $\mathrm{Pz}$ were first added to $500 \mathrm{~mL}$ of a $0.08 \mathrm{M}$ $\mathrm{FeCl}_{3} \cdot 6 \mathrm{H}_{2} \mathrm{O}$ solution. Then, the solution $\mathrm{pH}$ value was raised to 7.5 with $0.3 \mathrm{M} \mathrm{NaOH}$ and maintained for $3 \mathrm{~h}$ under vigorous stirring. The mixture was filtered, washed three times with demineralized water and then dried at room temperature for two days. For the second method ("wet contact" method), $20 \mathrm{~g}$ of $\mathrm{Pz}$ were mixed with $500 \mathrm{~mL}$ of water containing $2 \mathrm{~g}$ of pristine Fh in a $1 \mathrm{~L}$ plastic wide necked bottle for $12 \mathrm{~h}$. Afterward, the mixture was filtered and dried at room temperature for two days. For the third method ("dry contact" method), different weight of pristine $\mathrm{Fh}$, ranging from 1 to $12 \mathrm{~g}$, were placed in a $500 \mathrm{~mL}$ plastic wide necked bottle with $20 \mathrm{~g}$ of $\mathrm{Pz}$ and the mixture was shaken for $12 \mathrm{~h}$. A Reax 20/8 overhead shaker (Heidolph Instruments GmbH \& Co.KG, Schwabach, Germany) was used for the "wet contact" and "dry contact" methods and the rotation speed was $16 \mathrm{rpm}$. The Fh-Pz was, for the three different methods, subjected to the separation of free particles with a 40 mesh sieve. Weighing was finally carried out for each method to determine the weight of Fh coating by difference with the initial weight of $\mathrm{Pz}$ used for experiments.

The surface morphology of $\mathrm{Pz}$ and Fh-Pz was characterized using a JEOL JSM-7600F scanning electron microscope (SEM, JEOL USA Inc., Peabody, USA) of $1 \mathrm{~nm}$ resolution with 
$15 \mathrm{kV}$ accelerating voltage and $10^{6}$ magnification. The chemical compositions of the samples were analyzed using energy dispersive analysis of X-ray (EDAX) unit attached with the SEM. The surface physicochemical properties of samples were examined with a KRATOS Axis Ultra X-ray photoelectron spectrometer (XPS, Kratos Analytical, Manchester, UK), using monochromatic $\mathrm{Al} \mathrm{K \alpha}$ radiation $(h v=1486.6 \mathrm{eV})$, operated at $150 \mathrm{~W}$. Spectra were collected at normal take-off angle $\left(90^{\circ}\right)$ and the analysis area was $700 \times 300 \mu \mathrm{m}^{2}$. Survey scans were recorded using an analyzer pass energy of $160 \mathrm{eV}$ and narrow scans using an analyser pass energy of $20 \mathrm{eV}$. Charge correction was carried out using the $\mathrm{C} 1 \mathrm{~s}$ core peak, setting adventitious carbon signal to $284.6 \mathrm{eV}$. O 1s spectra were fitted using a Shirley background and a Gaussian/Lorentzian (70/30) peak model.

\subsection{Batch adsorption experiments}

A $5 \mathrm{~g} \mathrm{~L}^{-1}$ phosphate stock solution from $\mathrm{NaH}_{2} \mathrm{PO}_{4} \cdot 2 \mathrm{H}_{2} \mathrm{O}$ was first prepared and then diluted with demineralized water to the targeted phosphate ions concentration. All the experiments were carried out by adding $1 \mathrm{~g} \mathrm{~L}^{-1}$ of $\mathrm{Fh}-\mathrm{Pz}$ in glassware containing the phosphate solution and by stirring on an orbital shaker at $100 \mathrm{rpm}$. The $\mathrm{pH}$ was adjusted with $0.1 \mathrm{M} \mathrm{HCl}$ or $0.1 \mathrm{M} \mathrm{NaOH}$ solutions and the ionic strength was kept constant at $0.1 \mathrm{M}$ with $\mathrm{NaCl}$.

Phosphate adsorption kinetics were examined in $1 \mathrm{~L}$ Erlenmeyer flasks at $\mathrm{pH}=6 \pm$ 0.1 , using an initial phosphate ions concentration ranging from 10 to $100 \mathrm{PO}_{4} \mathrm{mg} \mathrm{L}^{-1}$ and for $24 \mathrm{~h}$. Such concentration level is relatively close to the concentration generally measured in wastewater $\left(\sim 1\right.$ to $\left.\sim 10 \mathrm{mg} \mathrm{PO}_{4} \mathrm{~L}^{-1}\right)$. An additional experience of 20 days was performed without stirring, with a $100 \mathrm{mg} \mathrm{L}^{-1}$ phosphate ions concentration. Phosphate adsorption isotherm experiments were carried out at $\mathrm{pH}=6 \pm 0.1$ in $100 \mathrm{~mL}$ Erlenmeyer flasks containing $50 \mathrm{~mL}$ varying initial concentrations of phosphate solutions $\left(0-225 \mathrm{mg} \mathrm{PO}_{4} \mathrm{~L}^{-1}\right)$. 
The effect of $\mathrm{pH}$ on phosphate sorption was examined with a similar procedure using a 100 $\mathrm{mg} \mathrm{PO}_{4} \mathrm{~L}^{-1}$ solution while maintaining $\mathrm{pH}$ at different values in the range $4-9$. The reaction period for isotherms experiments and $\mathrm{pH}$ effect was limited to $24 \mathrm{~h}$, this time period having been previously determined from kinetics experiments as sufficient for reaching equilibrium conditions. Sorption experiments conducted with uncoated $\mathrm{Pz}$ showed negligible phosphate sorption $\left(<1 \mathrm{mg} \mathrm{PO}_{4} \mathrm{~L}^{-1}\right.$ at a $\mathrm{pH}=7$ after $24 \mathrm{~h}$ reaction time $)$.

After appropriate contact time, $3 \mathrm{~mL}$ of mixture were filtered through $0.22 \mu \mathrm{m}$ polypropylene syringe filters and then analyzed by Inductively Coupled Plasma - Atomic Emission Spectrometry (ICP-AES) using an Ultima spectrometer (HORIBA Jobin Yvon SAS, Palaiseau, France), to determine the residual concentration of phosphate. Emission line at $213.618 \mathrm{~nm}$ was used in the evaluation experiment and the measurements were carried out with an accuracy of $0.055 \mathrm{mg} \mathrm{PO}_{4} \mathrm{~L}^{-1}$. The quantity of adsorbed phosphate ions onto $\mathrm{Fh}$ coating was calculated by the depletion method, as explained in our previous works $[6,15]$.

\subsection{Column adsorption experiments}

The column studies were set up to evaluate the sorption behavior of phosphate onto the filter material under flow-through conditions. Breakthrough column experiments are detailed further in the SI. Briefly, $55 \mathrm{~g}$ of dry Fh-Pz were packed into glass chromatographic columns of $2.6 \mathrm{~cm}$ internal diameter to give a uniform bulk density of $0.96 \pm 0.03 \mathrm{~g} \mathrm{~cm}^{-3}$. The flow direction was from the bottom to the top to ensure water-saturated conditions. The packing conditions of the five series of column are summarized in Table S1.

For each experiment, the columns were wetted with a background electrolyte solution $(\mathrm{NaCl}, 0.01 \mathrm{M})$ at a low flow rate $\left(0.2 \mathrm{~mL} \mathrm{~min}^{-1}\right)$. The packed columns were thus preequilibrated by pumping the background electrolyte solution for at least $24 \mathrm{~h}$, until the different parameters $\left(\mathrm{pH}\right.$, conductivity) became constant. The pore volume $\left(V_{\mathrm{p}}\right)$ was then 
calculated as the weight difference between dry and water-saturated column. Once the column became water-saturated, the flow characteristics of the filter material were determined by a non-reactive tracer experiment. The columns were fed upwards at a constant flow rate with a pulse of $5 \mathrm{~mL}$ of $\mathrm{KBr}$ solution $(0.01 \mathrm{M})$. Bromide ions concentration in the outflow was measured by ICP-AES.

Modeling of bromide experimental data was performed to determine the hydrodynamic parameters. Analyses can be done using two models, the classical ConvectionDispersion Equation (CDE) and the Mobile-Immobile Model (MIM) [23]. The common assumptions to both models are a constant porosity over time and no chemical and/or structural material evolution along the breakthrough test. The first (CDE) is a classical model which is widely used to describe the $1 \mathrm{D}$ transport of a non-reactive solute under steady-state water flow in a saturated column. The fit of bromide elution curve provided estimations of the volumetric water content $(\phi)$ and dispersion coefficient $(D)$ that characterize flow homogeneity. The second model, MIM, describes the flow heterogeneity through water fractionation into a mobile phase and a stagnant immobile phase, with convection and dispersion in mobile water and a first-order solute exchange between mobile and immobile fractions due to molecular diffusion. More details can be found in the SI.

All sorption experiments were conducted with an influent concentration of $100 \mathrm{mg}$ $\mathrm{PO}_{4} \mathrm{~L}^{-1}$. Three column experiments were performed with demineralized water at $1,0.5$ and $0.1 \mathrm{~mL} \mathrm{~min}^{-1}$ flow rates, one was performed with wastewater at $0.5 \mathrm{~mL} \mathrm{~min}^{-1}$ flow rate and a last one with Ca-doped demineralized water at $0.5 \mathrm{~mL} \mathrm{~min}^{-1}$ flow rate. The calcium concentration of the last solution was $100 \mathrm{mg} \mathrm{L}^{-1}$, in order to have the same concentration as found in wastewater. The phosphate and iron concentrations in the outflow were measured by ICP-AES in a $0.1 \mathrm{M} \mathrm{HNO}_{3}$ acidic solution in order to solubilize eventual Fh particles. The 
$\mathrm{BTC}$ of phosphate ions were expressed as the relative aqueous concentration $\left(C / C_{\mathrm{i}}\right)$ against the number of pore volumes $\left(V / V_{\mathrm{p}}\right)$.

\section{Results and discussion}

\subsection{Preparation and characterization of the filter material}

\subsubsection{Optimization of the quantity of ferrihydrite deposited onto pozzolana}

The quantity of Fh coated onto $\mathrm{Pz}$ is strongly dependent on the preparation method. Indeed, almost no coating can be observed with the "reactive" method. In contrast, mixing $2 \mathrm{~g}$ of pristine Fh with $20 \mathrm{~g}$ of Pz results in 0.32 and $0.88 \mathrm{~g}$ of Fh deposited onto Pz by using the "wet" and the "dry contact" methods respectively. The differences observed in the adhesion of Fh onto Pz may be due to the mechanical/physical forces at the solid-solid interfaces [22]. One of the driving forces for coating preparation are the physical interactions due to the collision and friction of both Fh and Pz and are therefore significant for the "dry contact" method. As the "dry contact" method is the best to obtain a high-content of deposited Fh, various tests, with different weight of pristine Fh and a constant weight of $\mathrm{Pz}(20 \mathrm{~g})$, were carried out to optimize the preparation method. The pristine Fh weight / Pz weight ratio $\left(R_{\mathrm{Fh}: \mathrm{Pz}}\right)$ vary therefore from 5 to $60 \%$ (Fig. 1). Figure 1.a. shows that the weight of coated Fh reaches a maximum value of $3.1 \mathrm{~g}$ when $8 \mathrm{~g}$ of pristine Fh are mixed with $20 \mathrm{~g}$ of Pz. This value corresponds to a $R_{\mathrm{Fh}: \mathrm{Pz}}$ ratio of $40 \%$ that is not necessary to exceed in order to obtain the highest quantity of deposited Fh. Nevertheless, it is possible to optimize the process, i.e. to minimize the Fh "losses", when the initial weight ratio is $R_{\mathrm{Fh}: \mathrm{Pz}} \sim 15 \%$ (Fig. 1b). Indeed, in this case, $45 \%$ of pristine Fh is coated onto Pz. Furthermore, circulation of water at a $1 \mathrm{~L} \mathrm{~s}^{-1}$ flow rate through the filter material packed in a column shows that the Fh coating was not released in solution only for initial weight ratios $R_{\mathrm{Fh}: \mathrm{Pz}}$ lower than $20 \%$, i.e. when $1.7 \mathrm{~g}$ of $\mathrm{Fh}$ is coated onto $20 \mathrm{~g}$ of $\mathrm{Pz}$. If this limit is exceeded, significant amount of Fh particles are 
released into the outflow solution during $1 \mathrm{~L} \mathrm{~s}^{-1}$ flow-through experiments and the outflow is strongly rust-colored. Therefore, all the samples used for further phosphate sorption experiments, performed either in "batch" or in column, were prepared by using an optimized initial weight ratio $R_{\mathrm{Fh}: \mathrm{Pz}}$ of $20 \%$. The filter material contains then $8.5 \times 10^{-2} \mathrm{~g} \mathrm{Fh} / \mathrm{g} \mathrm{Pz}$ which corresponds to 8.5 wt. \%. Assuming $\mathrm{Fe}_{8.2} \mathrm{O}_{8.5}(\mathrm{OH})_{7.4} \cdot 3 \mathrm{H}_{2} \mathrm{O}$ as the chemical formula for Fh [24], the iron surface concentration is $5 \times 10^{-2} \mathrm{~g} \mathrm{Fe} / \mathrm{g} \mathrm{Pz}$, i.e. 5 wt.\% Fe. When calculations are performed using to the most reported Fh formulae, such as $5 \mathrm{Fe}_{2} \mathrm{O}_{3} \bullet x \mathrm{H}_{2} \mathrm{O}$ [16,17], $\mathrm{Fe}_{5} \mathrm{O}_{8} \mathrm{H} \bullet x \mathrm{H}_{2} \mathrm{O}[25,26], \mathrm{Fe}_{10} \mathrm{O}_{14}(\mathrm{OH})_{12} \bullet x \mathrm{H}_{2} \mathrm{O}$ [27,28], equivalent results are obtained. This iron content is much higher than those reported for Fh-coated sand. The highest iron surface concentrations, i.e. 0.07 wt.\% [29] and 0.34 wt.\% [21], are obtained for coatings produced through the "reactive" method. For comparison, the iron surface concentration for Fh-coated sand is only 0.09 wt.\% with the "dry contact" method [21].

\subsubsection{SEM-EDAX, XRD and XPS analyses of the filter material}

The SEM images of $\mathrm{Pz}$ and $\mathrm{Fh}-\mathrm{Pz}$, displayed in Figure 2, show the effectiveness of the "dry contact" method. Indeed, the honeycombed structure of Pz (Fig. 2a) is no more observed after coating (Fig. 2b). This confirms that not only Fh adheres at the Pz surface, but also forms aggregates that are embedded inside the alveoli. It explains also the higher quantity of Fh deposited onto $\mathrm{Pz}$ in comparison with sand that presents a much smoother surface [21,29]. The XRD analysis (Fig. S1) reveals that $\mathrm{Pz}$ is mainly composed of labradorite ( $\mathrm{Na}, \mathrm{Ca})(\mathrm{Al}, \mathrm{Si})_{4} \mathrm{O}_{8}$ (ICDD file \# 83-1371), but also contains diopside $\mathrm{CaMgSi}_{2} \mathrm{O}_{6}$ (ICDD file \# 78-1390), forsterite $\mathrm{Mg}_{2} \mathrm{SiO}_{4}$ (ICDD file \# 75-1446) and hematite $\alpha-\mathrm{Fe}_{2} \mathrm{O}_{3}$ (ICDD file \# 890599). This is in good agreement with the chemical elements detected by EDAX that reveals also traces of potassium and titanium (Table 2). After coating, the surface of the Fh coated $\mathrm{Pz}$ 
is mainly composed of iron and oxygen indicating that the Pz support is almost fully covered by the Fh aggregates.

Surface analyses were performed by XPS and highlight the same elements in both Pz and Fh-Pz (Fig. 3). The high resolution $\mathrm{O} 1 \mathrm{~s}$ spectrum of $\mathrm{Pz}$ consists of three components (inset of Fig. 3a). The first one observed at $530.2 \mathrm{eV}$ is in good agreement with the O-Fe bonds existing in hematite [30]. The most intense component at $531.3 \mathrm{eV}$ can be assigned to the metal-O-Si bonding present in labradorite [31], forsterite [32], and diopside [33]. The third component at $532.9 \mathrm{eV}$ can be attributed to the $\mathrm{Si}-\mathrm{O}-\mathrm{Si}$ bonding specifically present in diopside [33]. The high resolution $\mathrm{O} 1 \mathrm{~s}$ spectrum of $\mathrm{Fh}-\mathrm{Pz}$ displays three components at 529.7, 531.4 and $532.8 \mathrm{eV}$ (inset of Fig. 3b), but with different relative intensities compared to those obtained for Pz. This is due to the Fh coating as O1s spectrum of Fh is composed of a very intense peak at $529.7 \mathrm{eV}$, corresponding to $\mathrm{Fe}-\mathrm{O}$ bonding, a less intense peak at 531.1 $\mathrm{eV}$, corresponding to structural $\mathrm{OH}$ and a very low intense peak at $533 \mathrm{eV}$, corresponding to structural water [15]. On the contrary to the EDAX analysis, the main elements which characterized $\mathrm{Pz}$, i.e. Si and $\mathrm{Al}$, are still detected during the XPS analysis of the Fh-Pz sample (Table 2). This could be explained by the presence of uncoated zones situated at the top of the alveoli of Pz forming the surface cracking observed by SEM (Fig. 2b). Such uncoated area would be easily detected by XPS, the analysis area being of the same order of magnitude than the $\mathrm{Pz}$ grains, whereas the probability to detect such surface cracking with the electron beam of EDAX is very low.

\subsection{Batch adsorption experiments}

\subsubsection{Adsorption kinetics}

The phosphate adsorption kinetics onto the filter material at $\mathrm{pH}=6.0 \pm 0.1$ are illustrated in Figure 4a for three initial concentrations of phosphate. After very rapid sorption 
during the first $100 \mathrm{~min}$, phosphate uptake becomes slower and reaches a plateau at about 1

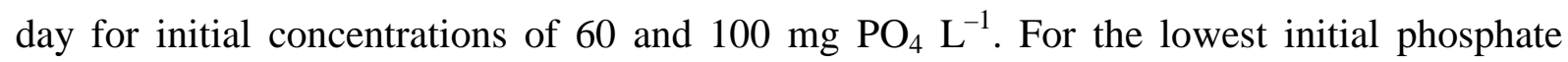
concentration, i.e. $10 \mathrm{mg} \mathrm{L}^{-1}$, the kinetics curve shows a plateau at around 100 minutes, reflecting the complete sorption of phosphate on the filter material. The maximal sorption capacity is $q_{\mathrm{e}, \mathrm{exp}} \sim 64 \mathrm{mg} \mathrm{PO}_{4} \mathrm{~g}^{-1}$ for an initial concentration of $100 \mathrm{mg} \mathrm{PO}_{4} \mathrm{~L}^{-1}$, which is below the value previously obtained at $\mathrm{pH}=6$ for the free Fh particles $\left(>80 \mathrm{mg} \mathrm{PO}_{4} \mathrm{~g}^{-1}\right.$ ) $[15,34]$. This suggests that the coating process may affect the sorption capacity through the following mechanisms: (i) surface binding process between Fe-phase and Pz material, and/or (ii) formation of dense aggregates of Fh particles inside the Pz alveoli as supposed from SEM images. Previous works showed that the coating process involving quartz sand has a minimal impact on the number of reactive surface sites of iron oxides [35-37]. However, the aggregation state of Fh nanoparticles seems to be of great importance in determining the sorption behavior on Fh surface [38].

In order to evaluate the kinetic sorption mechanism, pseudo-first-order, pseudosecond-order and Elovich models were tested. The pseudo-first order and Elovich models did not fit the phosphate sorption onto $\mathrm{Fh}-\mathrm{Pz}$ samples as low correlation coefficients were obtained $\left(R^{2}<0.983\right)$ and thus the data are not shown here. The pseudo-second order kinetic model [39] is expressed as:

$$
\frac{\mathrm{d} q_{\mathrm{t}}}{\mathrm{d} t}=k\left(q_{\mathrm{e}}-q_{\mathrm{t}}\right)^{2}
$$

where $q_{\mathrm{e}}$ and $q_{\mathrm{t}}$ are the quantity of adsorbed phosphate ions $\left(\mathrm{mg} \mathrm{g}^{-1}\right)$ at equilibrium and at defined time $t$ respectively, and $k$ is the apparent rate constant of sorption $\left(\mathrm{g} \mathrm{mg}^{-1} \mathrm{~min}^{-1}\right)$. After integrating Eq. (1), the linearized form can be expressed as:

$$
\frac{t}{q_{\mathrm{t}}}=\frac{1}{k q_{\mathrm{e}}^{2}}+\frac{t}{q_{\mathrm{e}}}
$$


The pseudo-second-order constants $k$ and $q_{\mathrm{e}}$ (Table 3) were calculated from the slope and intercept of the plots of $t / q_{\mathrm{t}}$ vs. $t$ (inset of Fig. 4a), using the linear least squares fitting technique. The plots show good linearity, with regression coefficients $R^{2}$ above 0.999 for the entire sorption period (Table 3). The kinetics of phosphate adsorption onto the filter material match very well the pseudo-second-order model, suggesting that the adsorption rate-limiting step may be a chemisorption process [39]. The values of constant $k$ and the product $k q_{\mathrm{e}}$ decrease as the initial phosphate concentration increases, suggesting different accessibility levels of the sorption surface sites. Indeed, at low phosphate ions concentration, only the most accessible sorption sites would interact with the phosphate anions. At higher concentrations and close to saturation, the number of free and easily accessible sites decreases which would slow down the adsorption process. In addition, the structure and organization of Fh aggregates present in the alveoli of $\mathrm{Pz}$ may also play a role in the determination of kinetic rates. Indeed, intra-aggregate diffusion could influence the slower adsorption step observed at $t$ values higher than 100 min [35]. Despite that similar shape has been observed for the kinetic curves, the $k$ values are slightly higher for free Fh particles [15] than those obtained with $\mathrm{Fh}-\mathrm{Pz}$, suggesting that the aggregation state of Fh may be modified upon coating process as compared to the free Fh particles.

In addition, an experiment was performed under static conditions to determine the influence of stirring on the phosphate sorption kinetics (Fig. 4.b). The kinetics curve can be described by two linear portions of time intervals $0-2$ and $2-19$ days, probably reflecting two different stages in the reaction mechanism: (i) a rapid phosphate sorption which is likely due to some easily accessible surface sites; (ii) slower step providing an additional gain of about $15 \mathrm{mg} \mathrm{PO}_{4} \mathrm{~g}^{-1}$, which is probably related to the intra-aggregate diffusion. Among the different kinetic models tested, the pseudo-second-order model again leads to the best correlation coefficient (Table 3). The value of the sorption capacity at equilibrium obtained 
after 18 days of contact time $\left(q_{\mathrm{e}, \exp }=59 \mathrm{mg} \mathrm{PO}_{4} \mathrm{~g}^{-1}\right)$ is relatively close to that obtained after 1 day of stirring $\left(67 \mathrm{mg} \mathrm{PO}_{4} \mathrm{~g}^{-1}\right)$. The value of kinetic constant is lower in static conditions $(k=$ $\left.1.1 \times 10^{-5} \mathrm{~g} \mathrm{mg}^{-1} \mathrm{~min}^{-1}\right)$ as compared to that determined under stirring conditions $(k=2.2 \times$ $10^{-5} \mathrm{~g} \mathrm{mg}^{-1} \mathrm{~min}^{-1}$ ), thereby underscoring the role of intra-aggregate diffusions and therefore the aggregation state of Fh particles.

\subsubsection{Adsorption isotherms}

Equilibrium sorption studies were conducted at $\mathrm{pH}=6 \pm 0.1$ to assess phosphate ions distribution between the filter material and aqueous phase as a function of phosphate ions concentration (Fig. 5). The sorption isotherm shape is very similar to that previously observed for free Fh particles $[15,40]$. The Freundlich isotherm allows the best fitting $\left(R^{2}>0.997\right)$ in the entire phosphate ions concentration range examined $\left(0-225 \mathrm{mg} \mathrm{PO}_{4} \mathrm{~L}^{-1}\right)$. The sorption process corresponds thus to a heterogeneous system with different surface site affinities. The Freundlich equation can be expressed as follows:

$$
q_{\mathrm{e}}=K_{\mathrm{F}} C_{\mathrm{e}}^{n}
$$

where $C_{\mathrm{e}}$ is the concentration of phosphate ions in solution $\left(\mathrm{mg} \mathrm{L}^{-1}\right)$ at equilibrium, $K_{\mathrm{F}}$ represents the Freundlich affinity coefficient $\left(\operatorname{mg}^{\frac{n-1}{n}} \mathrm{~L}^{\frac{1}{n}} \mathrm{~g}^{-1}\right)$ and $n$ is the Freundlich linearity constant. The Freundlich linear form of Eq. (3) is therefore:

$$
\log \left(q_{\mathrm{e}}\right)=\log \left(K_{\mathrm{F}}\right)+n \log \left(C_{\mathrm{e}}\right)
$$

The plot of $\log \left(q_{\mathrm{e}}\right)$ vs. $\log \left(C_{\mathrm{e}}\right)$ enables determining the Freundlich constants (inset of Fig. 5). The values of $K_{\mathrm{F}}\left(23.3 \mathrm{mg}^{\frac{n-1}{n}} \mathrm{~L}^{\frac{1}{n}} \mathrm{~g}^{-1}\right)$ and $n(0.29)$ show a slightly less favorable phosphate ions sorption compared to the free Fh particles (26.9 $\mathrm{mg}^{\frac{n-1}{n}} \mathrm{~L}^{\frac{1}{n}} \mathrm{~g}^{-1}$ and 0.2 respectively) $[15,40]$. This data confirms the previous kinetic findings, i.e. the nature and structure of Fh 
aggregates particles, which determine the surface reactivity, are different between free Fh particles and Fh trapped inside $\mathrm{Pz}$ alveoli.

\subsubsection{Effect of $p H$}

The influence of $\mathrm{pH}$ on the phosphate ions sorption on $\mathrm{Fh}-\mathrm{Pz}$ was determined in the $\mathrm{pH}$ range $4-9$ (Fig. 6). The sorption amount decreases with increasing $\mathrm{pH}$ value, as it is widely observed for the sorption of anions onto iron oxides $[6,41,42]$. The maximum value of $89 \mathrm{mg} \mathrm{PO}_{4} \mathrm{~g}^{-1}$ is obtained at $\mathrm{pH}$ around 4 .

Thermodynamic sorption models, that use molecular-level details and surface speciation data, allow describing the sorption dependence upon $\mathrm{pH}$ [43]. Surface complexation models (SCM) utilize mass action laws, mass balance equations and chemical equilibrium speciation, analogous to aqueous phase complexation equilibria, to describe the formation of surface complexes [44,45]. The simplified models such as DDL, DLM, etc. present however some limitations: (i) it handles sorbates as point charges with no spatial extend; (ii) no Stern layer exists, implying that outer-sphere and inner-sphere sorption complexes cannot be distinguished and charge cannot be distributed over the surface complex. Recently, multisite surface complexation (MUSIC) and charge distribution (CD) models are developed to account for the surface heterogeneity and the charge distribution, respectively [43]. Generally, the chemical heterogeneity of the minerals surface and spatial charge distribution at the interface solid/solution strongly influence the ions adsorption process $[46,47]$. As will be shown below, molecular-level details of the speciation of phosphate at the iron oxide surface exist. This available data motivated the use of a mechanistic and molecular approach in the present study. In addition, this approach (CD-MUSIC) is now implemented in PHREEQC-2 geochemical transport modeling software [48]. The phosphate anions sorption onto iron oxides is described by three or four types of surface complexes [34]. Spectroscopic 
investigations performed by using infrared spectroscopy [49-51] and X-ray Absorption Near Edge Structure (XANES) spectroscopy [52] led to the conclusion that essentially protonated and deprotonated bidentate complexes are formed at Fh surfaces. The probable presence of protonated monodentate complexes in small proportion at acidic $\mathrm{pH}$ and nonprotonated only at very alkaline $\mathrm{pH}$ is also suggested [34]. In the present work, only the protonated and deprotonated bidentate complexes are considered.

On the other hand, various surface functional groups of oxide surface, i.e. singly $\left(\equiv \mathrm{FeOH}^{1 / 2-}\right)$, doubly $\left(\equiv \mathrm{Fe}_{2} \mathrm{OH}^{0}\right)$ and triply $\left(\equiv \mathrm{Fe}_{3} \mathrm{O}^{1 / 2-}\right)$ coordinated [47], may be involved in the formation of such complexes. However, the $\equiv \mathrm{Fe}_{2} \mathrm{OH}^{0}$ group is not to be considered in the $\mathrm{pH}$ range used in the present study because on the basis of Pauling's bond valence principle, it can become neither protonated nor deprotonated and the triply coordinated surface group involvement in surface complexation reactions is minor [34,53]. Thus, only the $\equiv \mathrm{FeOH}^{-1 / 2}$ group has to be considered for modeling the phosphate anions sorption onto the Fh surface. Therefore the chemical equations considered here are:

$$
\begin{aligned}
& \equiv 2 \mathrm{FeOH}^{-1 / 2}+2 \mathrm{H}^{+}+\mathrm{PO}_{4}^{3-} \leftrightarrow \equiv \mathrm{Fe}_{2} \mathrm{O}_{2}^{-1+\Delta \mathrm{z}_{0}} \mathrm{PO}_{2}^{\Delta \mathrm{z}_{1}}+2 \mathrm{H}_{2} \mathrm{O} \\
& \equiv 2 \mathrm{FeOH}^{-1 / 2}+3 \mathrm{H}^{+}+\mathrm{PO}_{4}^{3-} \leftrightarrow \equiv \mathrm{Fe}_{2} \mathrm{O}_{2}^{-1 / 2+\Delta \mathrm{z}_{0}} \mathrm{POOH}^{\Delta \mathrm{z}_{1}}+2 \mathrm{H}_{2} \mathrm{O}
\end{aligned}
$$

where $\Delta \mathrm{z}_{0}$ and $\Delta \mathrm{z}_{1}$ represent the change of the charge at 0 - and 1-planes respectively.

The CD-MUSIC model has recently been used in particular by Antelo et al. to describe the phosphate anions sorption onto Fh as a function of the $\mathrm{pH}[34] . \Delta \mathrm{z}_{0}, \Delta \mathrm{z}_{1}, C_{1}$ and $C_{2}$ (capacitances) values, estimated by Antelo et al. [34], are used to fit the phosphate ions sorption curve as a function of $\mathrm{pH}$ (Fig. 6). The surface complexation constants $\left(\log K_{\text {int }}\right)$ for protonated and nonprotonated bidentate complexes are 31.6 and 26.5 respectively (Table 4) and are relatively close to those reported in the literature for free Fh particles, equal to 32.09 and 27.78 respectively [34]. A good agreement is observed between the experimental data and the calculated curve except at high $\mathrm{pH}$ value, i.e. $\mathrm{pH}=9$ (Fig.6). This suggests that the 
consideration of only two bidentate complexes permits an accurate description of sorption edges in the $\mathrm{pH}$ range (4-8). Moreover, the monodentate complexes have a minor contribution since their integration into the CD-MUSIC model does not improve significantly the experimental curve fitting.

\subsection{Column adsorption experiments}

\subsubsection{Bromide tracer experiments}

The pulse injection of bromide produces a slightly asymmetry elution curve with a little tailing (Fig. S2). Measurements of bromide effluent concentration indicated that bromide ion did not interact with the packed material, and so the mass balance is good.

The hydrodynamic parameters of the saturated columns have been first determined using CDE developed on MATHCAD Professional software (Parametric Technology Corporation, Needham, USA). Values of $\phi, \mathrm{D}$, the Darcy velocity $(q)$, and water velocity ( $v)$ are given in Table $S 2$. The macroscopic dispersivity $\lambda$ is of about $0.34 \mathrm{~cm}$, which is the same order of magnitude than the grain size of $\mathrm{Pz}$ (between $\sim 0.1$ and $\sim 0.3 \mathrm{~cm}$ ). The Peclet number Pe in the columns are found around 31, much lower than the values reported elsewhere for coated-sand packed columns $[35,37]$. Nevertheless, this data can indicate a convective regime but with a significant hydrodynamic dispersion of the solute. Modeling with the MIM code (mobile immobile water) that considers a mobile zone where flow is allowed, an immobile zone with no flow, and exchange of solute between the two zones by diffusion [54], has also been performed. Although the estimate for immobile water is around $15 \%\left(\phi_{\mathrm{im}}\right)$, this modeling does not improve considerably the fit (Fig.S2). Consequently, we consider that the classical convection-dispersion model (CDE) is a priori sufficient to describe solute transport in the packed column. Additionally, this assumption allows the use of the combined approach (CD- 
MUSIC and convective-dispersive regime) using PHREEQC-2 geochemical transport software, for phosphate breakthrough description.

\subsubsection{Sorption of phosphate ions under flow-through conditions from lab-contaminated} solutions

The BTC of phosphate ions and $\mathrm{pH}$ are shown in Figure 7 at three flow rates $(1,0.5$ and $0.1 \mathrm{~mL} \min ^{-1}$ ). The outflow $\mathrm{pH}$ values firstly rise until a maximum value situated between 8.1 and 9.5 depending on the flow rate, and then decrease. The increase of $\mathrm{pH}$ suggests a co-adsorption of phosphate anions and protons onto Fh surfaces, as expected from the surface complexation reactions (Eqs. (5) and (6)). The $\mathrm{pH}$ reaches the influent $\mathrm{pH}$ value when solute sorption achieves steady state and complete breakthrough.

The three BTC of phosphate ions show a more or less pronounced sigmoid shape (Fig. 7). The BTC are found to be dependent on flow rate, suggesting local equilibrium is not reached over the time-scale of the column experiment. Indeed, these curves do not overlap and the breakthrough point or retardation factor increases with decreasing flow rate. The breakthrough points lies at 17, 26 and $38 \mathrm{~V} / V_{\mathrm{p}}$, while total breakthrough occurs at about 220, 150 and 125 injected pore volumes for $1,0.5$ and $0.1 \mathrm{~mL} \mathrm{~min}^{-1}$ flow rates respectively. The two parts of the BTC, (1) from 0 to $50 \mathrm{~V} / V_{\mathrm{p}}$ and (2) $>50 \mathrm{~V} / V_{\mathrm{p}}$ became steeper at low flow rate

$\left(0.1 \mathrm{~mL} \mathrm{~min}^{-1}\right)$. This BTC shape dependence on flow rate may result from several factors: (i) sorption kinetic effect, (ii) slow diffusion rate between two zones or phases, and/or (ii) significant hydrodynamic dispersion [23,53-55]. The BTC of phosphate, normalized by its retardation factor to that of the Bromide tracer, confirms that there is an influence of sorption kinetics, especially in the second stage of breakthrough (Fig. S3). Indeed, the normalized BTC coincides firstly with the tracer BTC, but it becomes more tilted than that of the tracer curve in the second stage (Fig. S3). This suggests that the first stage of phosphate breakthrough is 
mainly determined by dispersion, while the nonequilibrium sorption affects particularly the second one.

The analysis of BTC allows access to the sorption capacity for a given flow rate, which gives important information in determining whether the use of the filter material could be adapted to an industrial scale. This can be determined by two different methods (Fig. S4). The first method consists of setting the upper limit of the phosphate ions amount which may be released into the environment, i.e. $6 \mathrm{mg} \mathrm{PO}_{4} \mathrm{~L}^{-1}$ for sensitive areas subject to eutrophication as given by the Council Directive 91/271/EEC concerning urban wastewater treatment, and the filter material sorption capacity is then determined up to this value. The upper part of the BTC is thus integrated from $V / V_{\mathrm{p}}=0$ to the $V / V_{\mathrm{p}}$ value for $C / C_{\mathrm{i}}=0.06$. By using this method, the sorption capacity increases when the flow rate decreases, indicating the effect of phosphate sorption kinetic. Indeed, the calculated values are 14, 22 and $32 \mathrm{mg} \mathrm{PO}_{4}$ $\mathrm{g}^{-1}$ for $1,0.5$ and $0.1 \mathrm{~mL} \mathrm{~min}^{-1}$ flow rates respectively. Moreover, the concentration of phosphate in wastewater is generally lower than the value used in this study, i.e. $100 \mathrm{mg} \mathrm{PO}_{4}$ $\mathrm{L}^{-1}$, therefore breakthrough at higher values than $38 V / V_{\mathrm{p}}$ is expected for industrial applications. The second method requires integrating the entire upper part of the BTC, in order to obtain the total amount of phosphate ions adsorbed onto the filter material. In this case, the total sorption capacity is then equal to about $53 \mathrm{mg} \mathrm{PO}_{4} \mathrm{~g}^{-1}$ and is independent on flow rate. This value is, however, slightly lower than the value obtained under static batch condition (59 mg $\mathrm{PO}_{4} \mathrm{~g}^{-1}$ ) or stirred batch condition $\left(67 \mathrm{mg} \mathrm{PO}_{4} \mathrm{~g}^{-1}\right)$. This discrepancy between batch and column data can be attributed to several factors linked to the differences between batch and column experimental conditions: kinetic behavior of adsorption, loss of sorbent particles through transport, variations in column flow and moisture content and the presence of immobile water regions $[36,55]$. According to the Fe determination in the effluent by ICP, the first hypothesis can be ruled out since the loss of Fh particles is not detected. 
Furthermore, diffusion limitation may prevent phosphate anions to interact with the entire surface of Fh trapped in the bottom of Pz cavities.

Transport modeling has then been carried out with PHREEQC2 under the assumption of local equilibrium, using hydrodynamic parameters defined by a bromide tracer breakthrough experiment (Table S2) and the surface complexation parameters of this study (Table 4). The phosphate retention in column and in particular the breakthrough point can be successfully predicted through coupling aqueous transport (convection and dispersion) and the surface complexation model (batch experiments) (Fig. 8). The predicted BTC however fails to accurately describe the second part of the breakthrough (i.e. $\left.>50 \mathrm{~V} / V_{\mathrm{p}}\right)$ (Fig. 8). This partial disagreement between predicted and experimental BTC could possibly be related to the lack of local geochemical equilibrium in the column, and/or to diffusion phenomena between different zones in the column. Indeed, the extended tailing observed of the BTC, that is attenuated with decreasing flow rate (Fig. 7), let us suppose that the physical or chemical nonequilibrium effect is relatively significant. Unfortunately, these nonequilibrium effects cannot be taken into account in the combined approach implemented in PHREEQC2.

As the actual prediction can accurately describe the breakthrough point and particularly the phosphate sorbed amount till to the eutrophication limit, i.e. $6 \mathrm{mg} \mathrm{PO}_{4} \mathrm{~L}^{-1}$, we consider that the agreement between experimental and calculated BTC is satisfactory from both environmental and engineering points of view. Finally, this new modeling approach combining surface complexation modeling with molecular-level insights and macroscopic adsorption data could, nevertheless, describe the sorption of phosphate through a heterogeneous porous media. 


\subsubsection{Sorption of phosphate ions present in wastewater under flow-through conditions}

In order to test the sorption of phosphate under real conditions, a column test was carried out, at $0.5 \mathrm{~mL} \mathrm{~min}^{-1}$ flow rate, by using wastewater from sewage treatment plant as feed/influent solution. The physicochemical characteristics of the water sample supplied by a SAUR $^{\circledR}$ sewage treatment plant (Dombasle-sur-Meurthe, France) are reported in Table 1. Surprisingly, a high value of retardation factor is observed when phosphate-containing wastewater is used as feed solution (Fig. 9). Indeed, the breakthrough occurs at about $45 \mathrm{~V} / V_{\mathrm{p}}$ while it occurs at about $22 \mathrm{~V} / V_{\mathrm{p}}$ in the case of lab-contaminated solution (i.e. phosphate solution prepared in demineralized water). Within the $6 \mathrm{mg} \mathrm{PO}_{4} \mathrm{~L}^{-1}$ concentration limit not to exceed, the sorption capacity is about $42 \mathrm{mg} \mathrm{PO}_{4} \mathrm{~g}^{-1}$, and reaches the value of $80 \mathrm{mg} \mathrm{PO}_{4} \mathrm{~g}^{-1}$ for the entire BTC. Moreover, the presence of potential competitive anions in the water, including nitrate ions, does not seem to have any influence on the sorption capacity of the material, as it was previously observed for free Fh particles [15]. Additionally, the presence of organic matter in wastewater may compete with phosphate for the fixation on iron active sites. On the contrary, other compounds present in wastewater may increase the phosphate uptake by the filter material. As previously observed in literature, synergetic effect leading to an increase of the phosphate adsorption may exist between cationic calcium and phosphate ions on the surface of iron oxides [56].

The fixation of the positively charged $\mathrm{Ca}^{2+}$ ion on iron oxide surface may enhance the phosphate sorption through electrostatic interactions and modification of surface charge, as explained in Rietra et al. [57]. This synergy between the sorption of calcium and phosphate ions should be more pronounced at high $\mathrm{pH}$ values (> pzc of $\mathrm{Fh}$ ). In addition, both adsorption and precipitation reactions may take place depending on local geochemical conditions. For instance, the apatite, a calcium-phosphate mineral, may be formed in the system depending on $\mathrm{pH}$, calcium and phosphate ions loadings. 
To test the impact of calcium on phosphate sorption in our system ( $\mathrm{Fh}-\mathrm{Pz})$, a similar column was prepared as previously reported but injected with a feed solution containing 100 $\mathrm{mg} \mathrm{L}^{-1}$ of $\mathrm{Ca}^{2+}$ ions. A shift of the breakthrough point by a factor of about $\sim 3$ is observed as compared to that determined with Ca-free influent solution (Fig.9). This data corroborates that the presence of $\mathrm{Ca}^{2+}$ in wastewater increases the fixation of phosphate on Fh surfaces, and outweighs possible competitive effects of organic matter or other inorganic anions.

\section{Conclusion}

This work has successfully demonstrated that ferrihydrite-coated pozzolana is an efficient material for water dephosphatation. Phosphate anions introduced into water withdrawn from a sewage treatment plant was fully adsorbed on the surface of this material and a synergetic effect induced by soluble calcium species was observed. These results open new perspectives for passive water treatment technologies. Indeed, the material could be incorporated into horizontal filters located upstream from reed bed filters situated in rural areas. The optimized contact time between the material and the phosphate anions measured in this study $(\sim 7 \mathrm{~h})$ and the water hardness level are important factors that should be taken into account for the upscaling and then design of such reactors. The durability of the adsorption process should be studied as a function of new parameters such as the physicochemical and biological properties of water and the environmental conditions. Moreover, the increase of the concentration of calcium in water or inside the film deposited onto pozzolana may increase the phosphate adsorption capacity. Studying the phosphate adsorption capacity of pozzolana coated with calcium doped ferrihydrite could be the subject of future studies. 


\section{Acknowledgments}

The Agence Nationale de la Recherche (ANR program, ECOTECH2009 - N0994C0103) is gratefully acknowledged for financial support. K. Barthélémy expresses his sincere gratitude to SAUR for the Ph.D. position grant. The authors also acknowledge Dr. I. Bihannic (LEM, UMR 7569 CNRS - Université de Lorraine), A. Renard (LCPME, UMR 7564 CNRS Université de Lorraine) and L. Salsi (SCMEM, Université de Lorraine) for helping in the XRD, XPS and SEM-EDAX experiments respectively.

\section{References}

[1] C.C. Tanner, J.P.S. Sukias, T.R. Headley, C.R. Yates, R. Stott, Constructed wetlands and denitrifying bioreactors for on-site and decentralised wastewater treatment: Comparison of five alternative configurations, Ecol. Eng. 42 (2012) 112-123.

[2] W.H. Strosnider, B.K. Winfrey, R.W. Nairn, Biochemical oxygen demand and nutrient processing in a novel multi-stage raw municipal wastewater and acid mine drainage passive co-treatment system, Water Res. 45 (2011) 1079-1086.

[3] P. Molle, A. Lienard, A. Grasmick, A. Iwema, A. Kabbabi, Apatite as an interesting seed to remove phosphorus from wastewater in constructed wetlands, Water Sci. Technol. 51 (2005) 193-203.

[4] G. Lyngsie, O.K. Borggaard, H.C.B. Hansen, A three-step test of phosphate sorption efficiency of potential agricultural drainage filter materials, Water Res. 51 (2014) 256-265.

[5] Y. Kuwahara, S. Tamagawa, T. Fujitani, H. Yamashita, A novel conversion process for waste slag: synthesis of calcium silicate hydrate from blast furnace slag and its application as a versatile adsorbent for water purification, J. Mater. Chem. A 1 (2013) 7199-7210.

[6] K. Barthélémy, S. Naille, C. Despas, C. Ruby, M. Mallet, Carbonated ferric green rust as a new material for efficient phosphate removal, J. Colloid Interface Sci. 384 (2012) 121-127.

[7] A.F. de Sousa, T.P. Braga, E.C.C. Gomes, A. Valentini, E. Longhinotti, Adsorption of phosphate using mesoporous spheres containing iron and aluminum oxide, Chem. Eng. J. 210 (2012) 143-149.

[8] W. Driehaus, Method for producing a sorption material that contains iron, Patent WO2002047811 A1 (2002).

[9] I.N. Savina, C.J. English, R.L.D. Whitby, Y. Zheng, A. Leistner, S.V. Mikhalovsky, A.B. Cundy, High efficiency removal of dissolved As(III) using iron nanoparticle-embedded macroporous polymer composites, J. Hazard. Mater. 192 (2011) 1002-1008.

[10] K. Mandel, A. Drenkova-Tuhtan, F. Hutter, C. Gellermann, H. Steinmetz, G. Sextl, Layered double hydroxide ion exchangers on superparamagnetic microparticles for recovery of phosphate from waste water, J. Mater. Chem. A 1 (2013) 1840-1848. 
[11] J. Xie, Z. Wang, D. Wu, H. Kong, Synthesis and properties of zeolite/hydrated iron oxide composite from coal fly ash as efficient adsorbent to simultaneously retain cationic and anionic pollutants from water, Fuel 116 (2014) 71-76.

[12] M. Arias, J. Da Silva-Carballal, L. García-Río, J. Mejuto, A. Núñez, Retention of phosphorus by iron and aluminum-oxides-coated quartz particles, J. Colloid Interface Sci. 295 (2006) 65-70.

[13] Z.-1. Shi, F.-m. Liu, S.-h. Yao, Adsorptive removal of phosphate from aqueous solutions using activated carbon loaded with Fe(III) oxide, New Carbon Mater. 26 (2011) 299-306.

[14] S. Naille, K. Barthélémy, M. Mallet, C. Ruby, Method for producing a filtration material, Patent WO 2014032934 A1 (2014).

[15] M. Mallet, K. Barthélémy, C. Ruby, A. Renard, S. Naille, Investigation of phosphate adsorption onto ferrihydrite by X-ray photoelectron spectroscopy, J. Colloid Interface Sci. 407 (2013) 95-101.

[16] R.M. Cornell, U. Schwertmann, The iron oxides: Structure, properties, reactions, occurrences and uses, Wiley-VCH GmbH \& Co. KGaA, Weinheim, (2003).

[17] F.M. Michel, L. Ehm, G. Liu, W.Q. Han, S.M. Antao, P.J. Chupas, P.L. Lee, K. Knorr, H. Eulert, J. Kim, C.P. Grey, A.J. Celestian, J. Gillow, M.A.A. Schoonen, D.R. Strongin, J.B. Parise, Similarities in 2- and 6-line ferrihydrite based on pair distribution function analysis of X-ray total scattering, Chem. Mat. 19 (2007) 1489-1496.

[18] H. Guo, A.S. Barnard, Naturally occurring iron oxide nanoparticles: Morphology, surface chemistry and environmental stability, J. Mater. Chem. A 1 (2013) 27-42.

[19] S. Das, M.J. Hendry, J. Essilfie-Dughan, Transformation of two-line ferrihydrite to goethite and hematite as a function of $\mathrm{pH}$ and temperature, Environ. Sci. Technol. 45 (2010) 268-275.

[20] E.M. Moon, C.L. Peacock, Adsorption of $\mathrm{Cu}(\mathrm{II})$ to ferrihydrite and ferrihydrite-bacteria composites: Importance of the carboxyl group for $\mathrm{Cu}$ mobility in natural environments, Geochim. Cosmochim. Acta 92 (2012) 203-219.

[21] V. Khare, M. Mullet, K. Hanna, M. Blumers, M. Abdelmoula, G. Klingelhöfer, C. Ruby, Comparative studies of ferric green rust and ferrihydrite coated sand: Role of synthesis routes, Solid State Sci. 10 (2008) 1342-1351.

[22] M. Wencka, A. Jelen, M. Jagodič, V. Khare, C. Ruby, J. Dolinšek, Magnetic and EPR study of ferric green rust- and ferrihydrite-coated sand prepared by different synthesis routes, J. Phys. D-Appl. Phys. 42 (2009) 245301.

[23] M. Sardin, D. Schweich, F.J. Leij, M.T. van Genuchten, Modeling the nonequilibrium transport of linearly interacting solutes in porous media: A review, Water Resour. Res. 27 (1991) 2287-2307.

[24] F.M. Michel, V. Barron, J. Torrent, M.P. Morales, C.J. Serna, J.F. Boily, Q.S. Liu, A. Ambrosini, A.C. Cismasu, G.E. Brown, Ordered ferrimagnetic form of ferrihydrite reveals links among structure, composition, and magnetism, Proc. Natl. Acad. Sci. U. S. A. 107 (2010) 2787-2792.

[25] N. Pinney, J.D. Kubicki, D.S. Middlemiss, C.P. Grey, D. Morgan, Density functional theory study of ferrihydrite and related Fe-oxyhydroxides, Chem. Mat. 21 (2009) 5727-5742.

[26] K.M. Towe, W.F. Bradley, Mineralogical constitution of colloidal "hydrous ferric oxides”, J. Colloid Interface Sci. 24 (1967) 384-392. 
[27] F.M. Michel, L. Ehm, S.M. Antao, P.L. Lee, P.J. Chupas, G. Liu, D.R. Strongin, M.A.A. Schoonen, B.L. Phillips, J.B. Parise, The structure of ferrihydrite, a nanocrystalline material, Science 316 (2007) 1726-1729.

[28] S.J. Smith, K. Page, H. Kim, B.J. Campbell, J. Boerio-Goates, B.F. Woodfield, Novel synthesis and structural analysis of ferrihydrite, Inorg. Chem. 51 (2012) 6421-6424.

[29] M. Edwards, M.M. Benjamin, Adsorptive filtration using coated sand: A new approach for treatment of metal-bearing wastes, J. Water Pollut. Control Fed. 61 (1989) 1523-1533.

[30] J. Brillet, M. Gratzel, K. Sivula, Decoupling feature size and functionality in solutionprocessed, porous hematite electrodes for solar water splitting, Nano Lett. 10 (2010) 41554160.

[31] B. Plante, M. Benzaazoua, B. Bussière, M.C. Biesinger, A.R. Pratt, Study of Ni sorption onto Tio mine waste rock surfaces, Appl. Geochem. 25 (2010) 1830-1844.

[32] M.F. Hochella Jr, G.E. Brown Jr, Aspects of silicate surface and bulk structure analysis using X-ray photoelectron spectroscopy (XPS), Geochim. Cosmochim. Acta 52 (1988) 16411648.

[33] V.P. Zakaznova-Herzog, H.W. Nesbitt, G.M. Bancroft, J.S. Tse, High resolution core and valence band XPS spectra of non-conductor pyroxenes, Surf. Sci. 600 (2006) 3175-3186.

[34] J. Antelo, S. Fiol, C. Pérez, S. Mariño, F. Arce, D. Gondar, R. López, Analysis of phosphate adsorption onto ferrihydrite using the CD-MUSIC model, J. Colloid Interface Sci. 347 (2010) 112-119.

[35] K. Hanna, B. Rusch, L. Lassabatere, A. Hofmann, B. Humbert, Reactive transport of gentisic acid in a hematite-coated sand column: Experimental study and modeling, Geochim. Cosmochim. Acta 74 (2010) 3351-3366.

[36] B. Rusch, K. Hanna, B. Humbert, Sorption and transport of salicylate in a porous heterogeneous medium of silica quartz and goethite, Environ. Sci. Technol. 44 (2010) 24472453.

[37] B. Rusch, K. Hanna, B. Humbert, Coating of quartz silica with iron oxides: Characterization and surface reactivity of iron coating phases, Colloid Surf. A-Physicochem. Eng. Asp. 353 (2010) 172-180.

[38] I.R. Willett, C.J. Chartres, T.T. Nguyen, Migration of phosphate into aggregated particles of ferrihydrite, J. Soil Sci. 39 (1988) 275-282.

[39] Y.S. Ho, G. McKay, Pseudo-second order model for sorption processes, Process Biochem. 34 (1999) 451-465.

[40] X.M. Wang, F. Liu, W.F. Tan, W. Li, X.H. Feng, D.L. Sparks, Characteristics of phosphate adsorption-desorption onto ferrihydrite: Comparison with well-crystalline $\mathrm{Fe}$ (hydr)oxides, Soil Sci. 178 (2013) 1-11.

[41] R. Chitrakar, S. Tezuka, A. Sonoda, K. Sakane, K. Ooi, T. Hirotsu, Phosphate adsorption on synthetic goethite and akaganeite, J. Colloid Interface Sci. 298 (2006) 602-608.

[42] J. Kim, W. Li, B.L. Philips, C.P. Grey, Phosphate adsorption on the iron oxyhydroxides goethite $(\alpha-\mathrm{FeOOH})$, akaganeite $(\beta-\mathrm{FeOOH})$, and lepidocrocite $(\gamma-\mathrm{FeOOH}): A{ }^{31} \mathrm{P}$ NMR study, Energy Environ. Sci. 4 (2011) 4298-4305.

[43] T. Hiemstra, W.H. Van Riemsdijk, On the relationship between charge distribution, surface hydration, and the structure of the interface of metal hydroxides, J. Colloid Interface Sci. 301 (2006) 1-18. 
[44] J.A. Davis, J.A. Coston, D.B. Kent, C.C. Fuller, Application of the surface complexation concept to complex mineral assemblages, Environ. Sci. Technol. 32 (1998) 2820-2828.

[45] C.J. Tadanier, M.J. Eick, Formulating the charge-distribution multisite surface complexation model using FITEQL, Soil Sci. Soc. Am. J. 66 (2002) 1505-1517.

[46] T. Hiemstra, J.C.M. De Wit, W.H. Van Riemsdijk, Multisite proton adsorption modeling at the solid/solution interface of (hydr)oxides: A new approach: II. Application to various important (hydr)oxides, J. Colloid Interface Sci. 133 (1989) 105-117.

[47] T. Hiemstra, W.H. Van Riemsdijk, A surface structural approach to ion adsorption: The Charge Distribution (CD) model, J. Colloid Interface Sci. 179 (1996) 488-508.

[48] D.L. Parkhurst, C.A.J. Appelo, User's guide to PHREEQC (Version 2)--A computer program for speciation, batch-reaction, one-dimensional transport, and inverse geochemical calculations, Water-resources investigations report 99-4259, 1999.

[49] Y. Arai, D.L. Sparks, ATR-FTIR spectroscopic investigation on phosphate adsorption mechanisms at the ferrihydrite-water interface, J. Colloid Interface Sci. 241 (2001) 317-326.

[50] B.C. Barja, M.I. Tejedor-Tejedor, M.A. Anderson, Complexation of methylphosphonic acid with the surface of goethite particles in aqueous solution, Langmuir 15 (1999) 23162321 .

[51] C. Luengo, M. Brigante, J. Antelo, M. Avena, Kinetics of phosphate adsorption on goethite: Comparing batch adsorption and ATR-IR measurements, J. Colloid Interface Sci. 300 (2006) 511-518.

[52] N. Khare, J.D. Martin, D. Hesterberg, Phosphate bonding configuration on ferrihydrite based on molecular orbital calculations and XANES fingerprinting, Geochim. Cosmochim. Acta 71 (2007) 4405-4415.

[53] K. Hanna, J.F. Boily, Sorption of two naphthoic acids to goethite surface under flow through conditions, Environ. Sci. Technol. 44 (2010) 8863-8869.

[54] M.T. van Genuchten, P.J. Wierenga, Mass transfer studies in sorbing porous media I. Analytical solutions, Soil Sci. Soc. Am. J. 40 (1976) 473-480.

[55] K. Hanna, L. Lassabatere, B. Bechet, Transport of two naphthoic acids and salicylic acid in soil: Experimental study and empirical modeling, Water Res. 46 (2012) 4457-4467.

[56] M. Stachowicz, T. Hiemstra, W.H. van Riemsdijk, Multi-competitive interaction of $\mathrm{As}(\mathrm{III})$ and $\mathrm{As}(\mathrm{V})$ oxyanions with $\mathrm{Ca}^{2+}, \mathrm{Mg}^{2+}, \mathrm{PO}_{4}{ }^{3-}$, and $\mathrm{CO}_{3}{ }^{2-}$ ions on goethite, J. Colloid Interface Sci. 320 (2008) 400-414.

[57] R.P.J.J. Rietra, T. Hiemstra, W.H. van Riemsdijk, Interaction between calcium and phosphate adsorption on goethite, Environ. Sci. Technol. 35 (2001) 3369-3374. 


\section{Table 1}

Physico-chemical characteristics of wastewater measured by $\mathrm{SAUR}^{\circledR}$. $\mathrm{BOD}_{5}$ : five-day biochemical oxygen demand; COD: chemical oxygen demand; TSS: total suspended solids. Concentrations are expressed as $\mathrm{mg} \mathrm{L}^{-1}$.

\begin{tabular}{cccc}
\hline Parameter & Mean Value & Parameter & Mean Value \\
\hline $\mathrm{pH}$ & $6.9 \pm 0.1$ & Chlorides & $100 \pm 1$ \\
BOD $_{5}$ & $5.5 \pm 2.5$ & Nitrate & $5 \pm 0.1$ \\
$\mathrm{COD}$ & $14 \pm 1$ & Phosphate & $1 \pm 0.1$ \\
TSS & $5.5 \pm 2.5$ & Calcium & $95 \pm 1$ \\
Sulphate & $300 \pm 3$ & Magnesium & $29 \pm 0.4$ \\
\hline
\end{tabular}


Table 2

Elemental composition (at.\%) of pozzolana and Fh-Pz.

\begin{tabular}{ccccc}
\hline \multirow{2}{*}{ Element } & \multicolumn{2}{c}{ EDAX (at.\%) } & \multicolumn{2}{c}{ XPS (at.\%) } \\
\cline { 2 - 5 } & $\mathrm{Pz}$ & $\mathrm{Fh}-\mathrm{Pz}$ & 69.46 & Ph-Pz \\
\hline $\mathrm{O}$ & 63.67 & 50.36 & 0.70 & - \\
$\mathrm{Na}$ & 1.37 & - & 0.52 & - \\
$\mathrm{Mg}$ & 1.65 & - & 7.01 \\
$\mathrm{Al}$ & 9.55 & 0.22 & 16.80 & 3.81 \\
$\mathrm{Si}$ & 17.44 & 0.62 & 0.47 & - \\
$\mathrm{K}$ & 0.42 & - & 1.02 & - \\
$\mathrm{Ca}$ & 2.01 & - & 0.57 & - \\
$\mathrm{Ti}$ & 0.74 & - & 2.15 & 13.16 \\
$\mathrm{Fe}$ & 3.15 & 48.80 & & \\
\hline
\end{tabular}




\section{Table 3}

Kinetic parameters for phosphate adsorption onto filter material $\left(\mathrm{pH}=6\right.$; $[\mathrm{Fh}-\mathrm{Pz}]=1 \mathrm{~g} \mathrm{~L}^{-1}$; $\left.\left[\mathrm{Cl}^{-}\right]=0.1 \mathrm{M}\right)$.

\begin{tabular}{|c|c|c|c|c|}
\hline \multirow{2}{*}{$\begin{array}{l}\text { Phosphate initial } \\
\text { concentration }\left(\mathrm{mg} \mathrm{L}^{-1}\right)\end{array}$} & \multicolumn{3}{|c|}{ Pseudo-second order kinetic parameters } & \multirow{2}{*}{$\begin{array}{c}q_{\mathrm{e}, \mathrm{exp}} \\
\left(\mathrm{mg} \mathrm{g}^{-1}\right)\end{array}$} \\
\hline & $k\left(\mathrm{~g} \mathrm{mg}^{-1} \min ^{-1}\right)$ & $q_{\mathrm{e}, \mathrm{cal}}\left(\mathrm{mg} \mathrm{g}^{-1}\right)$ & $R^{2}$ & \\
\hline $10^{\mathrm{a}}$ & $138 \times 10^{-4}$ & 9.6 & 0.999 & 9.5 \\
\hline $60^{\mathrm{a}}$ & $3.6 \times 10^{-4}$ & 56.4 & 0.999 & 55.1 \\
\hline $100^{\mathrm{a}}$ & $2.2 \times 10^{-4}$ & 66.8 & 0.998 & 64.2 \\
\hline $100^{\mathrm{b}}$ & $1.3 \times 10^{-5}$ & 59.3 & 0.999 & 57.1 \\
\hline
\end{tabular}

a: under stirring conditions; b: under static conditions 


\section{Table 4}

Surface species and CD-MUSIC parameters for proton, electrolyte and phosphate adsorption onto the filter material surface using the extended Stern layer model with $C_{1}=0.74 \mathrm{~F} \mathrm{~m}^{-2}$ and $C_{2}=0.93 \mathrm{~F} \mathrm{~m}^{-2} . \Delta \mathrm{z}_{0}, \Delta \mathrm{z}_{1}$ and $\Delta \mathrm{z}_{2}$ represent the change of the charge at 0-, 1- and 2-planes respectively; $K_{\text {int }}$ represents the surface complexation constant.

\begin{tabular}{lllll}
\hline Surface reactions & $\Delta \mathrm{z}_{0}$ & $\Delta \mathrm{z}_{1}$ & $\Delta \mathrm{z}_{2}$ & $\log K_{\text {int }}$ \\
\hline$\equiv \mathrm{FeOH}^{-1 / 2}$ & 0 & 0 & 0 & 0 \\
$\equiv \mathrm{FeOH}_{2}^{+1 / 2}$ & +1 & 0 & 0 & 9 \\
$\equiv \mathrm{FeOH}_{2}^{+1 / 2}-\mathrm{Cl}^{-}$ & +1 & -1 & 0 & 9 \\
$\equiv \mathrm{FeOH}^{-1 / 2}-\mathrm{Na}^{+}$ & 0 & +1 & 0 & -1 \\
$\equiv \mathrm{Fe}_{2} \mathrm{O}_{2}^{-1+\Delta \mathrm{z}_{0}} \mathrm{PO}_{2}^{\Delta \mathrm{z}_{1}}$ & 0.46 & -1.46 & 0 & 26.5 \\
$\equiv \mathrm{Fe}_{2} \mathrm{O}_{2}^{-1+\Delta \mathrm{z}_{0}} \mathrm{POOH}^{\Delta \mathrm{z}_{1}}$ & 0.63 & -0.63 & 0 & 31.6 \\
\hline
\end{tabular}


Figure Captions
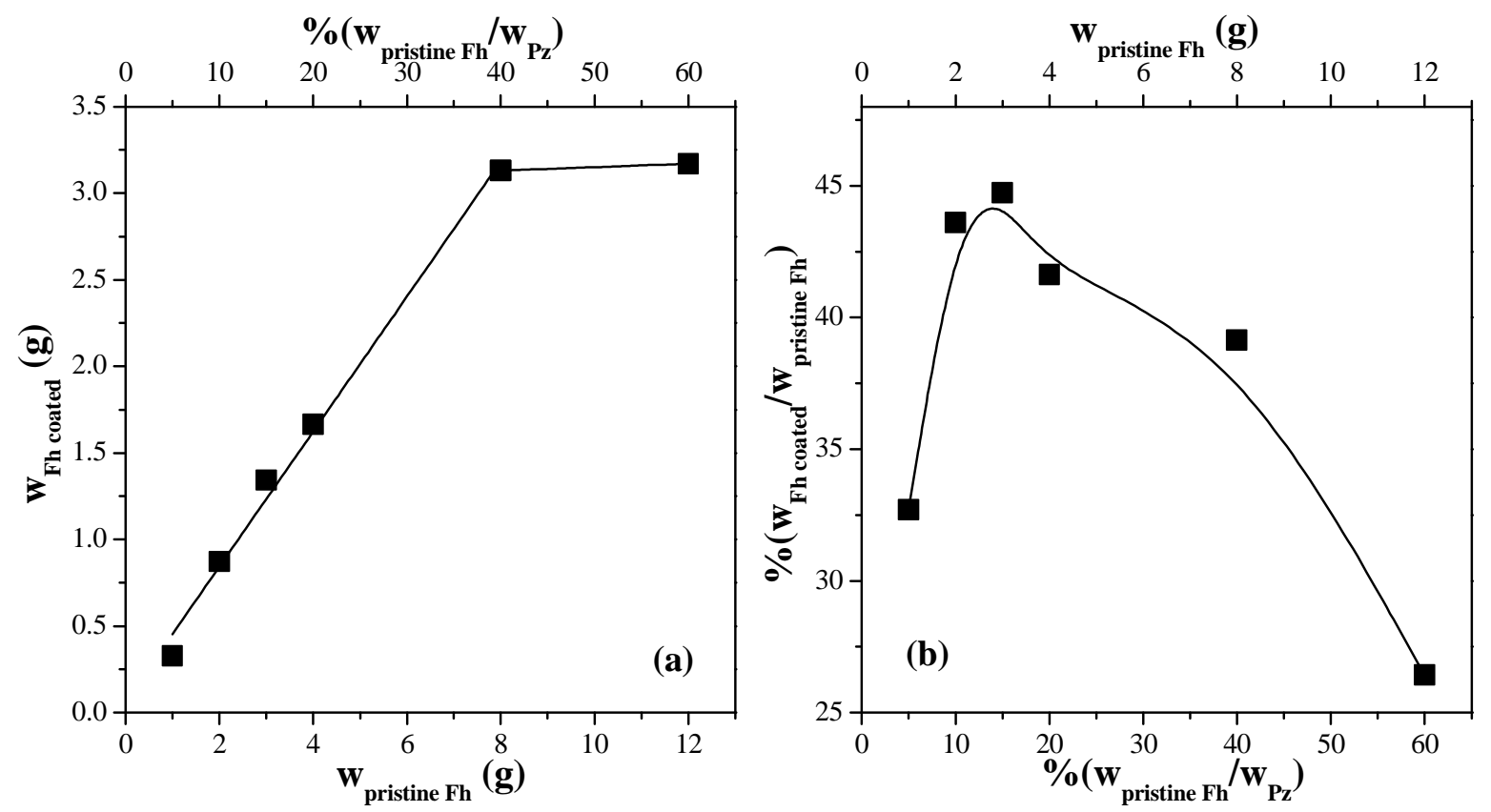

Fig. 1. (a) Weight of ferrihydrite-coated onto pozzolana as a function of the pristine ferrihydrite weight used for mixture and (b) ferrihydrite-coated onto pozzolana weight / pristine ferrihydrite weight ratio as a function of initial weight ratio. 

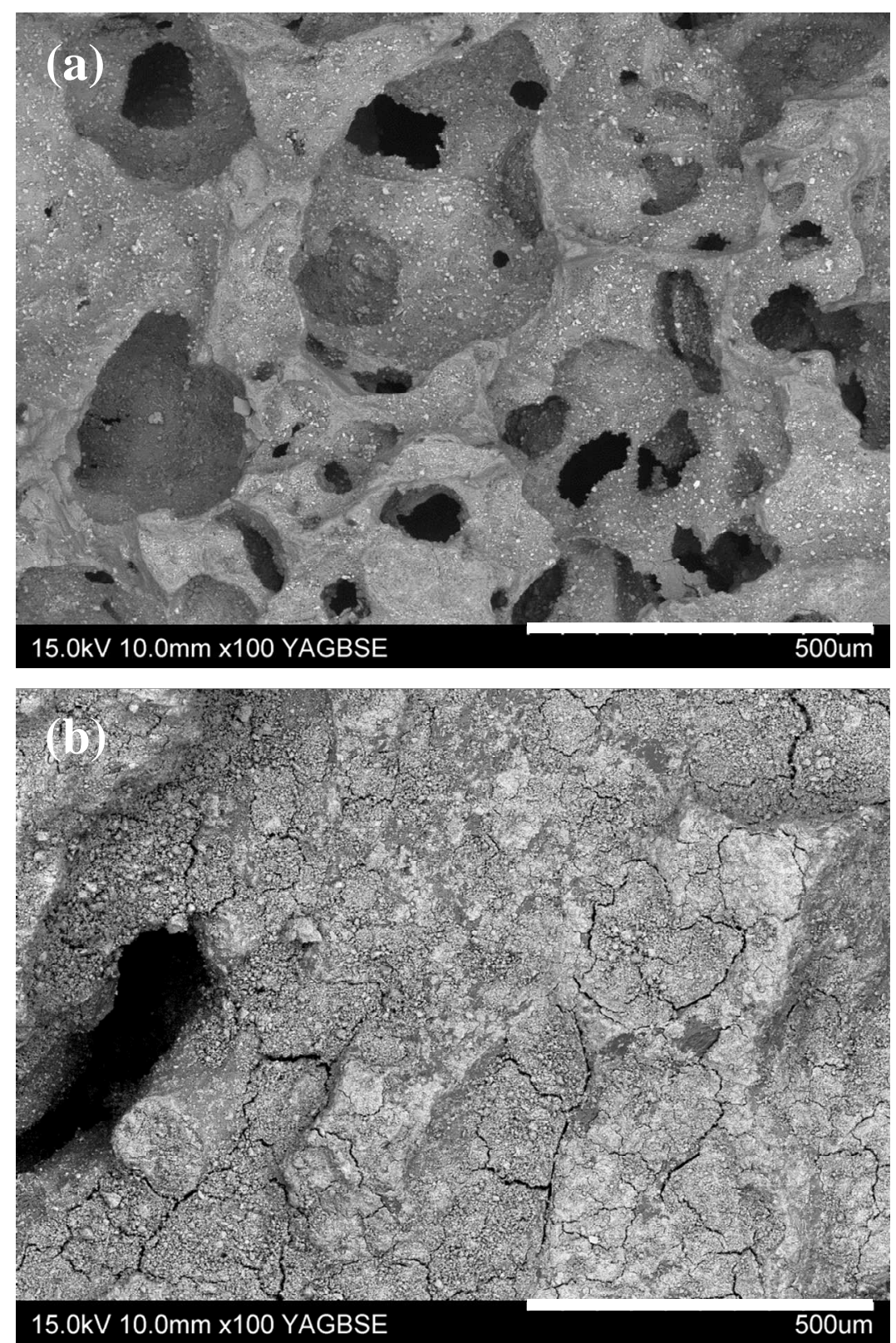

Fig. 2. SEM images of (a) pozzolana and (b) ferrihydrite-coated pozzolana. 


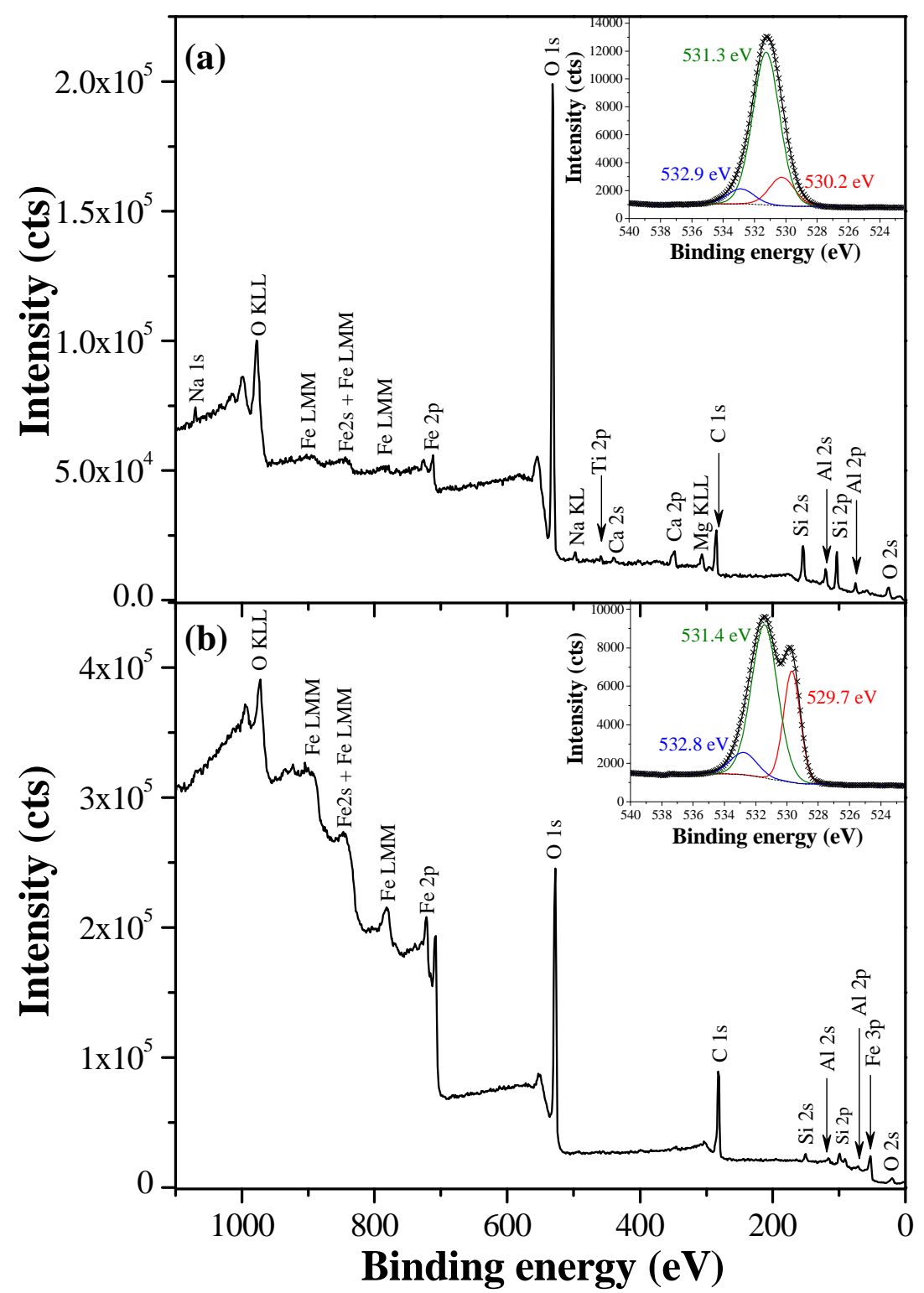

Fig. 3. XPS survey spectra of (a) pozzolana and (b) ferrihydrite-coated pozzolana. The corresponding $\mathrm{O} 1 \mathrm{~s}$ core levels are shown in insets. 

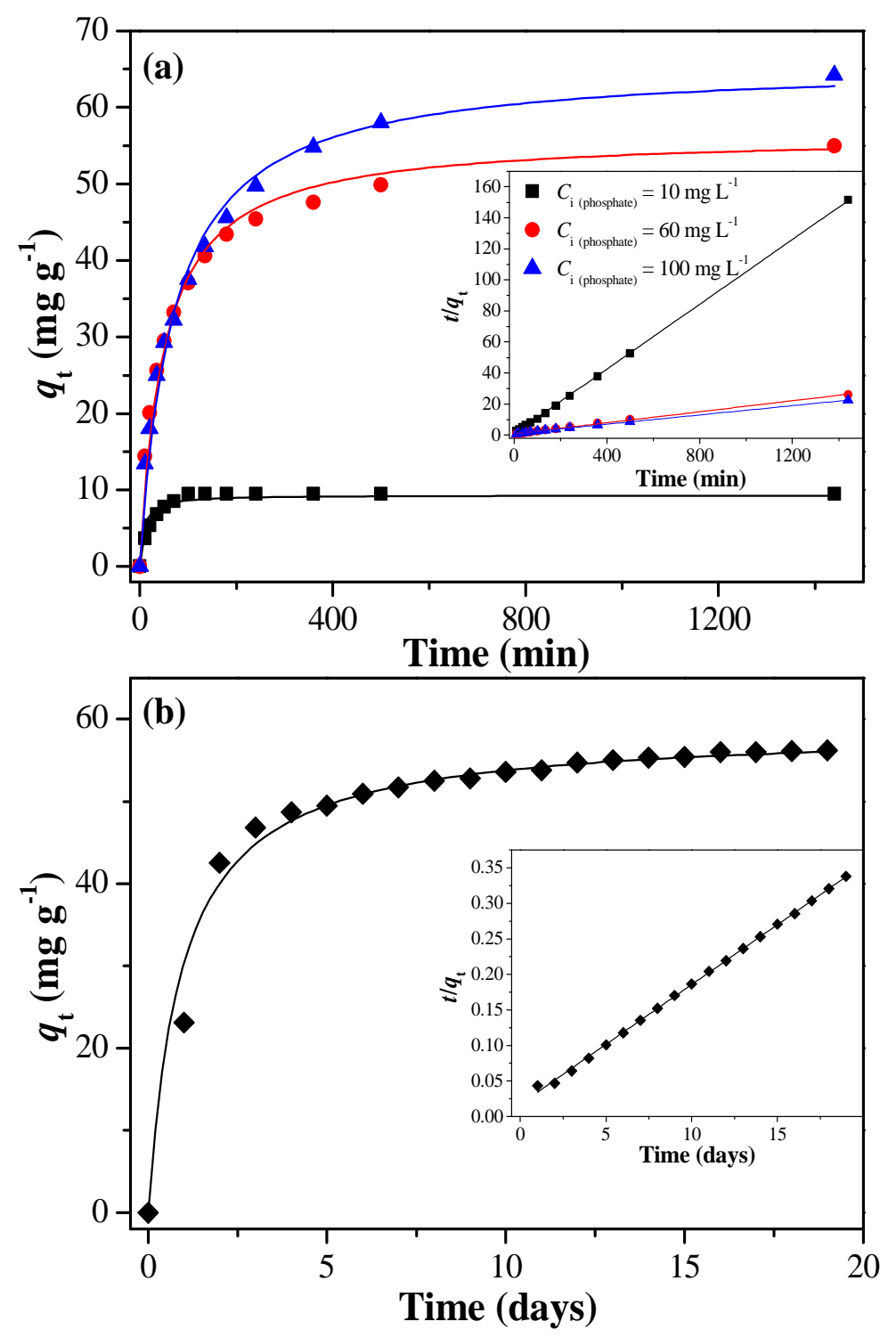

Fig. 4. Kinetic adsorption curves for phosphate ions uptake onto the filter material (a) under stirring and (b) in static mode ( $\mathrm{pH}=6 \pm 0.1$; $\left.[\mathrm{Fh}-\mathrm{Pz}]=1 \mathrm{~g} \mathrm{~L}^{-1} ;\left[\mathrm{Cl}^{-}\right]=0.1 \mathrm{M}\right)$. Relationships between $t / q_{\mathrm{t}}$ vs. time to verify the pseudo-second order model are given in insets. Symbols: experimental data; lines: pseudo-second order kinetic model fitting. 


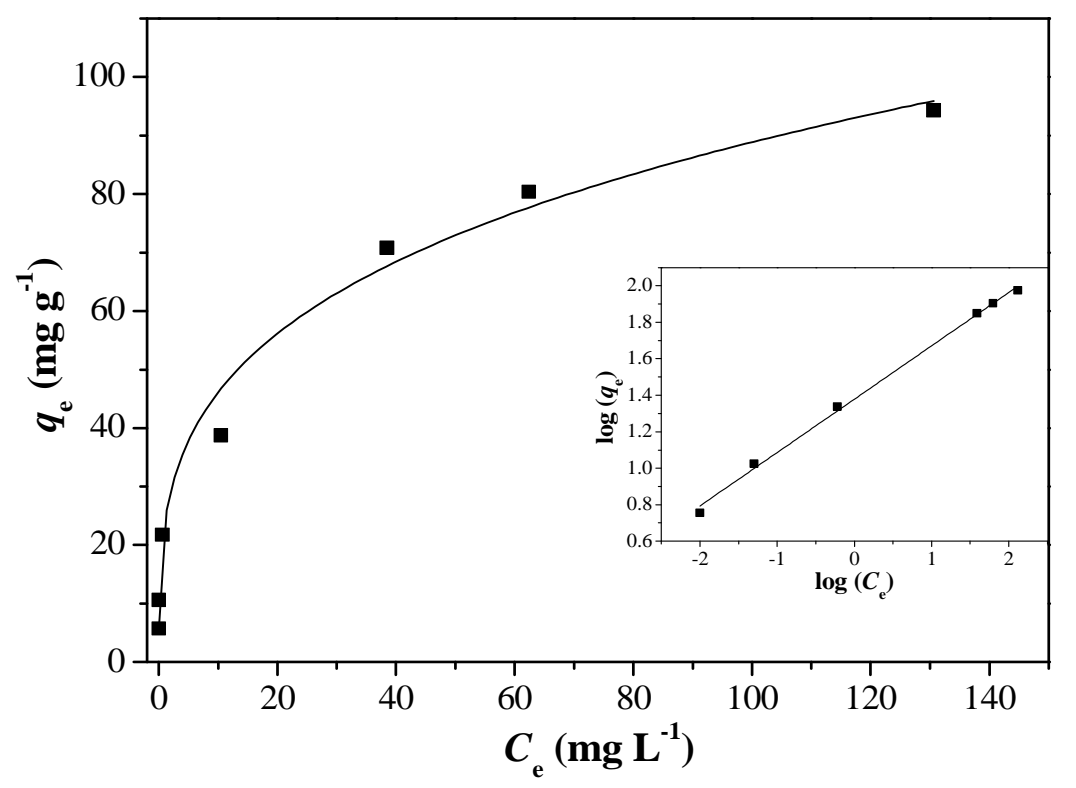

Fig. 5. Sorption isotherm of phosphate ions, after $24 \mathrm{~h}$ reaction time, onto the filter material $\left(\mathrm{pH}=6 \pm 0.1 ;[\mathrm{Fh}-\mathrm{Pz}]=1 \mathrm{~g} \mathrm{~L}^{-1} ;\left[\mathrm{Cl}^{-}\right]=0.1 \mathrm{M}\right)$. Relationship between $\log \left(q_{\mathrm{e}}\right)$ vs. $\log \left(C_{\mathrm{e}}\right)$ to verify the Freundlich model is given in inset. Symbols: experimental data; lines: Freundlich isotherms model fitting.

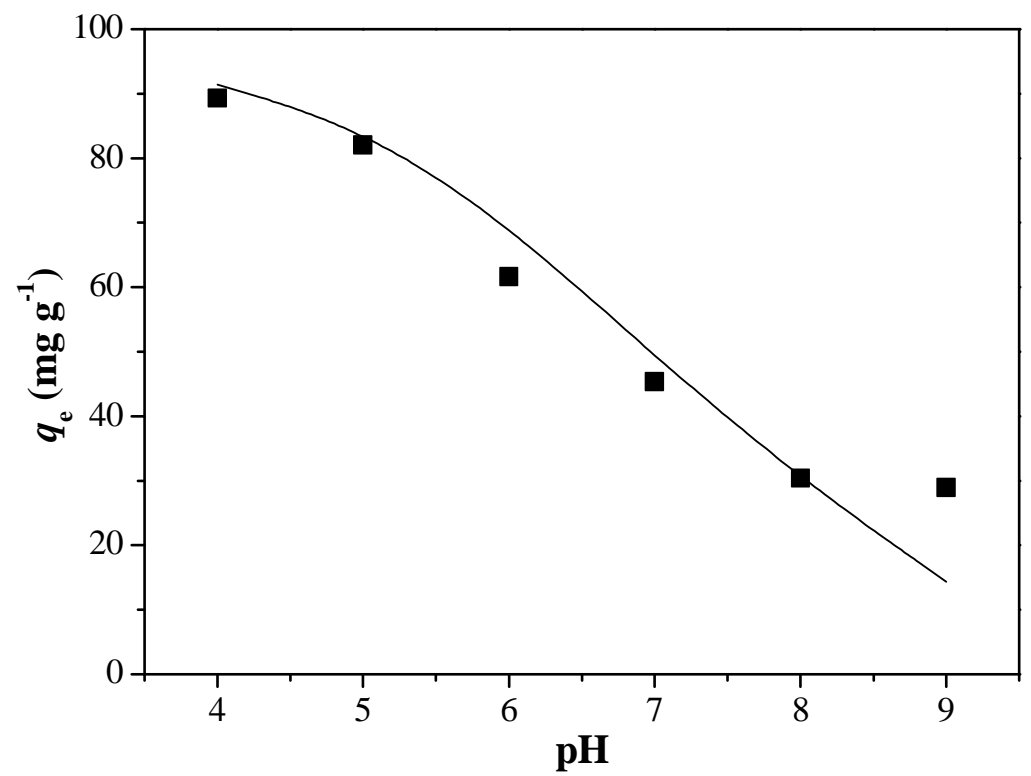

Fig. 6. Effect of $\mathrm{pH}$, after $24 \mathrm{~h}$ reaction time, on phosphate adsorption capacity $\left(q_{e}\right)$ by the filter material $\left(\left[\mathrm{PO}_{4}\right]=100 \mathrm{mg} \mathrm{L}^{-1} ;[\mathrm{Fh}-\mathrm{Pz}]=1 \mathrm{~g} \mathrm{~L}^{-1} ;\left[\mathrm{Cl}^{-}\right]=0.1 \mathrm{M}\right)$. Symbols: experimental data; lines: CD-MUSIC model fitting. 


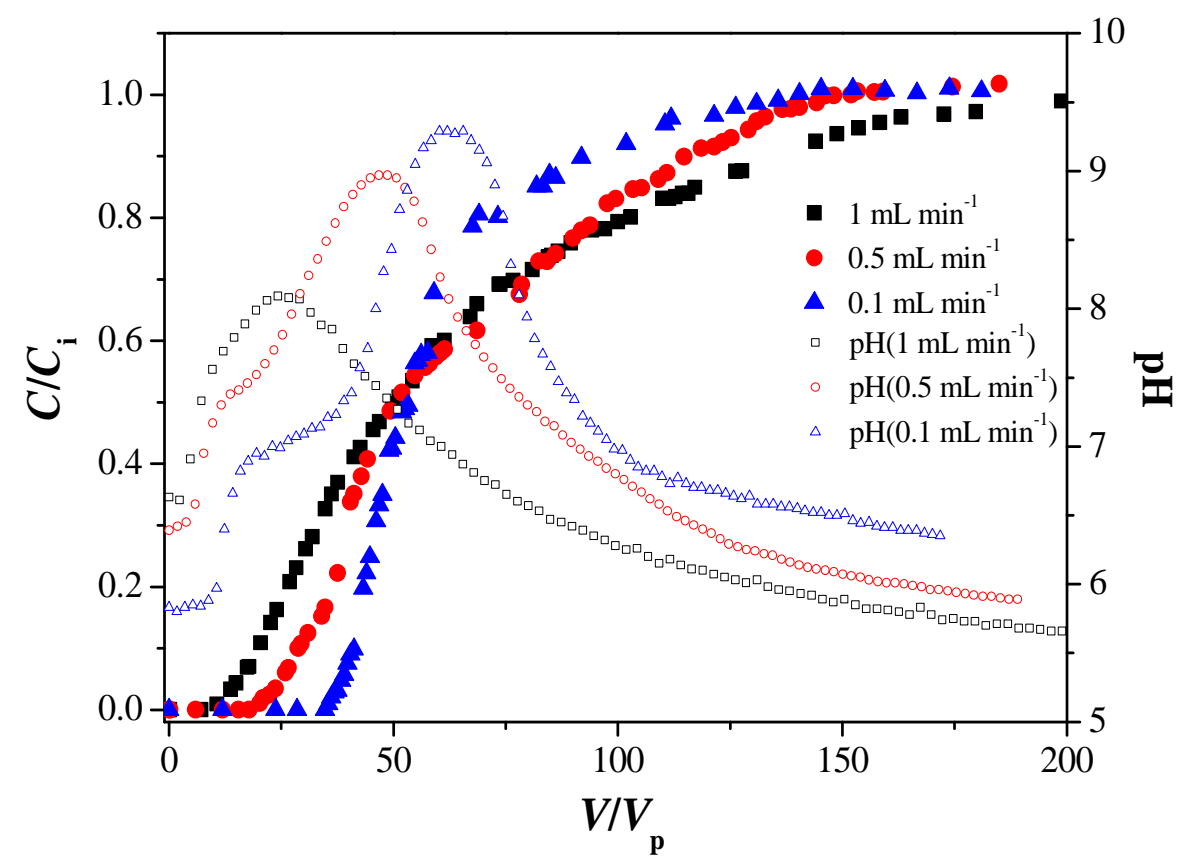

Fig. 7. Experimental breakthrough curves of phosphate ions and $\mathrm{pH}$ for the filter materialpacked columns at $1,0.5$ and $0.1 \mathrm{~mL} \mathrm{~min}^{-1}$ flow rates $\left(\left[\mathrm{PO}_{4}\right]=100 \mathrm{mg} \mathrm{L}^{-1} ;\left[\mathrm{Cl}^{-}\right]=0.1 \mathrm{M}\right)$.

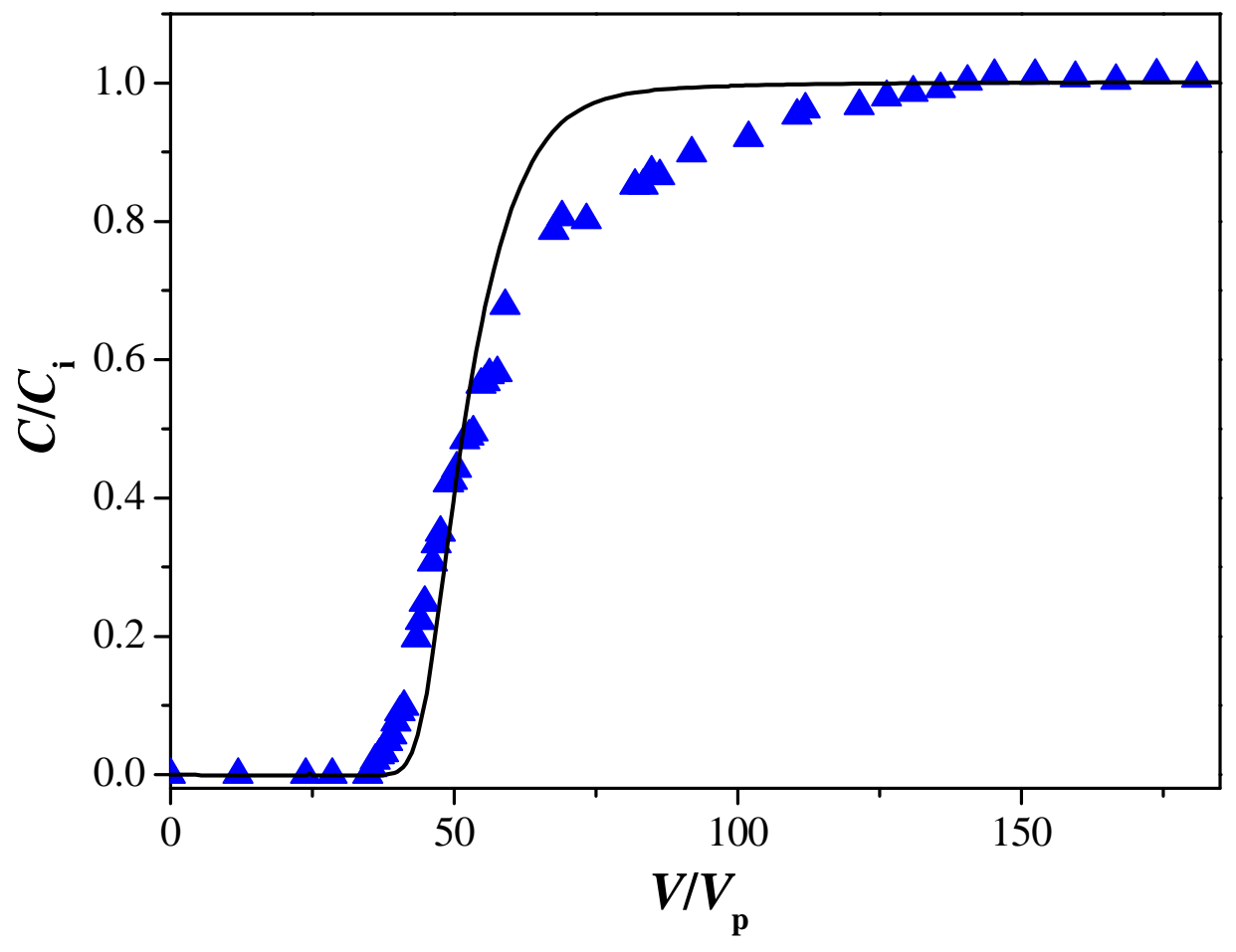

Fig. 8. Breakthrough curve of phosphate ions for the filter material-packed column at $0.1 \mathrm{~mL}$ $\min ^{-1}$ flow rates $\left(\left[\mathrm{PO}_{4}\right]=100 \mathrm{mg} \mathrm{L}^{-1} ;\left[\mathrm{Cl}^{-}\right]=0.1 \mathrm{M}\right)$. Symbols: experimental data; lines: calculated BTC. 


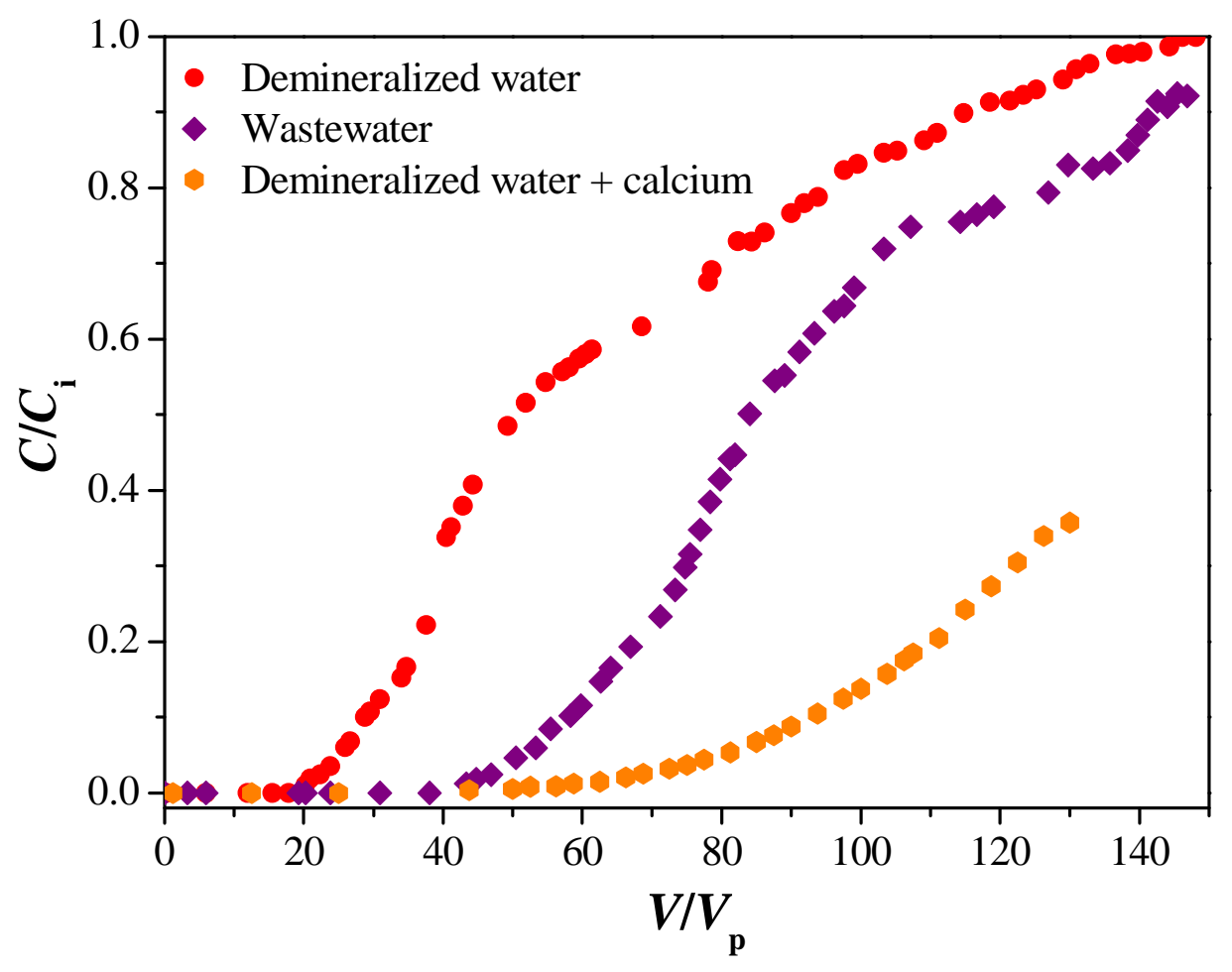

Fig. 9. Breakthrough curves of phosphate ions for the filter material-packed columns at 0.5 $\mathrm{mL} \min ^{-1}$ flow rate with demineralized water, wastewater and Ca-doped demineralized water $\left(\left[\mathrm{PO}_{4}\right]=100 \mathrm{mg} \mathrm{L}^{-1}\right.$ for all experiments; $\left[\mathrm{Cl}^{-}\right]=0.1 \mathrm{M}$ except for experiment with wastewater; $\left[\mathrm{Ca}^{2+}\right] \sim 100 \mathrm{mg} \mathrm{L}^{-1}$ except for experiment with demineralized water). 